\title{
Taxonomic revision of Niviventer (Rodentia, Muridae) from Vietnam: a morphological and molecular approach
}

\author{
Alexander E. Balakirev, Alexei V. Abramov \& Viatcheslav V. Rozhnov
}

\begin{abstract}
Based on a comparative investigation of morphological and genetic data, a taxonomic revision of the genus Niviventer in Vietnam and the adjacent regions of East Indochina was carried out. The phylogenetic relationships within 13 species ( $N$. andersoni, N. excelsior, N. eha, N. brahma, N. culturatus, $N$. coninga, $N$. rapit, $N$. niviventer, $N$. confucianus, $N$. tenaster, $N$. fulvescens, $N$. langbianis and $N$. cremoriventer) were investigated based on a full set of cytochrome $b$ sequences and the cytochrome coxidase subunit I genes that are currently available. The full species rank for $N$. huang and N. bukit, which previously were regarded as forms of $N$. fulvescens, was approved. The occurrence of the members of the Malayan complex of species ( $N$. tenaster, $N$. bukit and N. cremoriventer) among the mammal fauna of Southern Vietnam was established. The geographical distribution of the genetic lineages/species in Indochina is specified. It was shown that eight Niviventer species, namely $N$. niviventer, $N$. confucianus, $N$. bukit, $N$. tenaster, $N$. fulvescens, $N$. huang, $N$. langbianis and $N$. cremoriventer, occur in Vietnam. Some species ( $N$. bukit, $N$. huang and $N$. langbianis) were demonstrated to be sympatrically distributed, whereas the others ( $N$. fulvescens $-N$. huang and, apparently, $N$. cremoriventer $-N$. langbianis) formed vicariate pairs. Four species ( $N$. niviventer, $N$. confucianus, $N$. fulvescens, and $N$. langbianis), were found to inhabit Northern Vietnam and the adjacent provinces of China (Yunnan, Guizhou); four species ( $N$. tenaster, $N$. bukit, $N$. huang and N. langbianis) were recorded in the mountain regions of Central Vietnam and Laos; and three others (N. bukit, N. cremoriventer and N. huang) were found to inhabit most of the plains in Indochina, including Southern Vietnam, Cambodia, and a part of Thailand. It should be stressed that $N$. huang (but not $N$. fulvescens as it is usually considered) is the most common Niviventer species in Indochina, and its distribution range stretches over the plains of Thailand, Cambodia and Vietnam up to the south-eastern provinces of China.

Craniometrical characters and indexes were studied by applying discriminant analysis; the species-specific pattern of skull proportions and its applicability for species identification were demonstrated for some of the characters and indexes. By morphological analysis of genetically verified specimens, morphologically detailed descriptions of the external appearance and structural traits of the skull were presented for all eight Vietnamese Niviventer species. Practical recommendations and guidelines for visual species identification are also given. The size of the body and skull, the comparative length and the specific pattern of coloration of the tail and tail tip as well as the dorsal side of the feet, the size and shape of the auditory bullae, the comparative length of the incisive foramina and the bony palatal bridge and the extent of development of supraorbital ridges were demonstrated to be the most informative features for species identification.
\end{abstract}

KEY WORDS: Niviventer, Muridae, Indochina, Vietnam, molecular phylogeny, taxonomy, morphological identification.

Alexander E.Balakirev [alexbalakirev@mail.ru] and ViatcheslavV.Rozhnov[rozhnov.v@gmail.com],A.N. Severtsov Institute of Ecology and Evolution, Russian Academy of Sciences, Leninskii pr. 33, Moscow 119071, Russia; Joint Vietnam-Russian Tropical Research and Technological Centre, Nguyen Van Huyen, Nghia Do, Cau Giay, Hanoi, Vietnam; Alexei V. Abramov [a.abramov@mail.ru], Zoological Institute, Russian Academy of Sciences, Universitetskaya nab. 1, Saint Petersburg 199034, Russia; Joint Vietnam-Russian Tropical Research and Technological Centre, Nguyen Van Huyen, Nghia Do, Cau Giay, Hanoi, Vietnam.

\section{Таксономическая ревизия рода Niviventer (Rodentia, Muridae) из Вьетнама: морфологический и молекулярный подход}

\section{А.Е. Балакирев, А.В. Абрамов, В.В. Рожнов}

РЕЗЮМЕ. На основе сравнительного исследования морфологических и молекулярно-генетических данных проведена таксономическая ревизия рода Niviventer Вьетнама и сопредельных территорий восточного Индокитая. Исследованы филогенетические взаимоотношения 13 видов (N. andersoni, $N$. excelsior, $N$. eha, $N$. brahma, $N$. culturatus, $N$. coninga, $N$. rapit, $N$. niviventer, $N$. confucianus, $N$. tenaster, $N$. fulvescens, $N$. langbianis и $N$. cremoriventer) с привлечением всех доступных в настоящее время последовательностей гена цитохрома $b$ и гена цитохромоксидазы. Подтвержден видовой 
статус $N$. huang и $N$. bukit, ранее рассматривавшихся в составе $N$. fulvescens. Установлено присутствие представителей малайского комплекса видов (N. tenaster, $N$. bukit и $N$. cremoriventer) в фауне Южного Вьетнама. Уточнено географическое распространение генетических линий/видов на территории Индокитая. Установлено, что на территории Вьетнама распространены 8 видов - $N$. niviventer, $N$. confucianus, $N$. bukit, $N$. tenaster, $N$. fulvescens, $N$. huang, $N$. langbianis и $N$. cremoriventer. Ряд видов (N. bukit, $N$. huang и $N$. langbianis) имеет симпатрическое распространение, другие виды (N. fulvescens - N. huang и, по-видимому, N. cremoriventer - N. langbianis) образуют строго викарирующие пары. В Северном Вьетнаме обитают четыре вида (N. niviventer, N. confucianus, $N$. fulvescens, и $N$. langbianis), распространённые также в приграничных провинциях Южного Китая (Юннань, Гуйжу). Четыре вида (N. tenaster, $N$. bukit, $N$. huang и $N$. langbianis) распространены в горных районах центрального Вьетнама и Лаоса. В равнинной части Индокитая — южном Вьетнаме, Камбодже и большей части Таиланда обитают три вида (N. bukit, N. cremoriventer и N. huang). Наиболее обычным видом в Индокитае следует признать $N$. huang (а не $N$. fulvescens, как это принято считать в настоящее время), ареал которого простирается по равнинным районам Таиланда, Камбоджи и Вьетнама вплоть до юго-восточных провинций Китая.

При помощи дискриминантного анализа исследованы краниометрические признаки и индексы, продемонстрирована видоспецифичность ряда пропорций черепа и возможность их использования для видовой диагностики. На основе морфологического анализа генетически идентифицированных экземпляров составлены подробные морфологические описания экстерьера и деталей строения черепа для вьетнамских видов Niviventer. Приводятся практические рекомендации по визуальной видовой диагностике. Наиболее информативными для видовой диагностики оказались общие размеры тела и черепа, относительная длина хвоста, характер окраски его ствола и окончания, особенности окраски дорсальной поверхности стопы, размер слуховых барабанов, относительная длина резцовых отверстий и костного нёба, степень развития супраорбитальных костных гребней.

КЛЮЧЕВЫЕ СЛОВА: Niviventer, Muridae, Индокитай, Вьетнам, молекулярная филогения, таксономия, морфологическое определение.

\section{Introduction}

The taxonomy of Niviventer, commonly known as white-bellied rats or niviventers, has been intensively debated during the last century. The majority of the species belonging to this genus were first described during the last decades of XIX or at the beginning of the XX century as representatives of the genera Rattus and Mus (Miller, 1900; Bonhote, 1903, 1906; Thomas, 1916; Robinson \& Kloss, 1922; Allen, 1926; Osgood, 1932). Allen (1940) and Ellerman (1941, 1947, 1948, 1949 , 1961) were the first to separate this group of species (Rattus niviventer group) within Rattus sensu lato. Subsequently, based on a comparative investigation of the structure of teeth, Misonne (1969) placed the entire niviventer group in the genus Maxomys. The first formal description of the genus/subgenus (although without designation of a type species) was performed by Marshall (1977), who placed new species (Rattus/ Niviventer hinpoon) in the group Rattus niviventer in agreement with Ellerman's taxonomy (Ellerman, 1941, 1947, 1948, 1949, 1961; Ellerman \& Morrison-Scott, 1951, 1966).

The species composition and the preliminary intrageneric structure in the genus Niviventer were first established by Musser (1981) through a general revision of Rattus sensu lato. As a result, the genera Niviventer, Maxomys, Leopoldamys, Lenotrix, Dacnomys and Chiromyscus were separated from Rattus based on features of the skull structure, such as the configuration of the lateral walls of the cranium just above each pterygoid fossa, details of the construction of the squamosal roots of the zygomatic arches, the position of the posterior margin of the palatal bridge against the third upper molars, details of the construction of the mesopterygoid fossa, the proportions of the auditory bullae and other specific skull structures. Moreover, the genus Niviventer is characterized by a specific karyotype with a greater diploid number $(2 n=46)$ than Rattus sensu stricto (Yong, 1969; Duncan et al., 1970; Duncan \& Van Peenen, 1971; Markvong et al., 1973; Yoshida, 1973; Bekasova, 1984). Thus, at the moment, the limits of the genus Niviventer can be considered as established, but, after five decades, there is still no agreement regarding species composition, taxonomic status and the number of forms that belong to this genus, and, especially, regarding the reciprocal correspondence of such forms.

Initially, Musser (1981) separated fifteen species within the genus Niviventer, which were subdivided into two groups/divisions: the "andersoni group" consisted of $N$. andersoni and N. excelsior, and the "niviventer group" included N. brahma, N. eha, N. langbianis, $N$. hinpoon, and $N$. cremoriventer. The taxonomic status of a large series of forms, namely $N$. niviventer, $N$. confucianus, $N$. tenaster, $N$. fulvescens, $N$. coninga, $N$. rapit, $N$. lepturus and $N$. bukit, was unclear, and this group was referred to as the "niviventer complex". However, in contrast to the "andersoni group" in which the species composition was well agreed upon, the composition of the "niviventer group" has remained 
unresolved for decades. The situation is unclear even concerning the type species, $N$. niviventer. For example, Ellerman \& Morrison-Scott (1961) treated N. niviventer as a morph of $N$. confucianus, whereas Neithammer \& Martens (1975) combined it with $N$. fulvescens and treated the latter as a Nepalese color morph of $N$. niviventer. Likewise, Ellerman (1941, 1947, 1948, 1949, $1961)$ treated $N$. tenaster as a larger geographic morph of $N$. cremoriventer, whereas the latter species had been synonymized with either $N$. niviventer or $N$. confucianus before it was separated as a different species. The species rank of $N$. langbianis was proposed by Musser (1973) and Marshall (1977) but challenged by Abe (1983). On the contrary, in the same paper, Abe (1983) asserted the position that $N$. bukit is a distinct species, not a morph of $N$. fulvescens, which was considered synonymous by authors. At the moment, a generic structure proposed by Musser (1981) is generally accepted in most recent reviews (Nowak, 1999; Wang, 2003; Pavlinov, 2005). As indicated in the most recent summary on the rodents taxonomy (Musser \& Carleton, 2005), the genus Niviventer comprises 17 species that are subdivided into the groups "andersoni" and "niviventer", with three additional species, N. culturaus, $N$. fraternus and $N$. cameroni, which are considered distinct species within the "niviventer group", and with $N$. bukit having no specific status. At the same time, recent investigations using molecular taxonomy based on the divergence of the cytochrome $b$ gene sequences show that the intrageneric structure within the genus Niviventer is much more complex than currently accepted; three or four additional monophyletic groups can be separated within the genus, and a large number of species are underestimated (Balakirev \& Rozhnov, 2010).

As a result of the long and complex taxonomic history of the genus Niviventer, complex and sometimes arbitrary synonymy has arisen. Currently, two (for $N$. tenaster) to twenty-six (for $N$. fulvescens) synonyms are listed for different Niviventer species (Musser \& Carleton, 1993, 2005; Pavlinov, 2005). Many of them are considered morphs of different species, which significantly complicates the situation. Moreover, the morphological features of many of the species listed in different reviews (Corbet \& Hill, 1992; Kuznetsov, 2006; Francis, 2008; Smith \& Lunde, 2008) are vague and unclear or even contradictory. This makes it especially difficult for zoologists to identify rats that are collected in the field. There is a great array of mammalogists' opinions regarding the species composition and assignment of different morphs that compose the genus Niviventer, making it difficult to compare the results obtained by independent researchers.

It should be noted that the taxonomic problems mentioned above mainly arise from issues with the intrageneric taxonomy that was built based on traditionally accepted morphological traits. However, the general appearance and many of the skull features among species of this genus are quite similar. Great efforts have been made to apply karyological techniques to resolve some of these taxonomic problems. Unfortunately, a success has been limited due to the considerable difficulties of applying these methods in the field and the great similarity in chromosomal numbers among the majority of the species. Chromosome numbers $(2 n)$ for most of species were found to be equal to 46 with a fundamental number (NF) ranging from 52 to 66 (Yong, 1969; Duncan et al., 1970; Duncan \& Van Peenen, 1971; Markvong et al., 1973; Yoshida, 1973; Bekasova, 1984; Jiang, 1995; Li et al., 2008). The majority of individual chromosomes are difficult to distinguish even in differentially stained preparations arranged in rows of progressively diminished metacentrics.

As genomic investigations have become increasingly common, new higher resolution molecular methods are applied to resolve taxonomic problems. Nevertheless, only a few papers based on large numbers of species have been published (Jing et al., 2007; Balakirev \& Rozhnov, 2010; Pagés et al., 2010) to date. There are still no complex investigations of the genus Niviventer that include both traditional morphological and modern genetic approaches. Therefore, many of the genetically characterized materials have been misidentified and often contradict with the generally accepted taxonomy and nomenclature. A large series of genetic samples deposited in the international databases (GenBank, EMBL, DDBJ) have been misidentified and have not been subjected to comprehensive taxonomic verification; this situation not only fails to provide taxonomic clarity, but, on the contrary, also causes additional confusions. Taking into consideration the points mentioned above, the main purpose of this study was to perform a taxonomic analysis within the genus Niviventer in East Indochina based on both morphological and genetic data and to elaborate a practical guide and recommendations for specific identification of Niviventer in the region.

\section{Materials and methods}

Specimens deposited at the Zoological Museum of Moscow State University (ZMMU, Moscow) and the Zoological Institute of the Russian Academy of Sciences (ZIN, Saint-Petersburg) and the personal collections of authors were investigated. In total, 62 skulls and 24 alcohol-preserved bodies of adult specimens of Niviventer spp. (Fig. 1, APPENDIXES I-II) were studied. All specimens were collected during field surveys of the Joint Vietnam-Russian Tropical Research and Technological Centre in Southern and Northern Vietnam.

Morphological data. The age of the animals was defined by scoring morphological features, such as general size and body proportions, genital development and the level of teeth wear. All individuals obtained in the field were weighed, measured and photographed just after animals being sacrificed. Weights were obtained with an electronic balance. Values for head and body length, length of the tail, length of the hind foot 


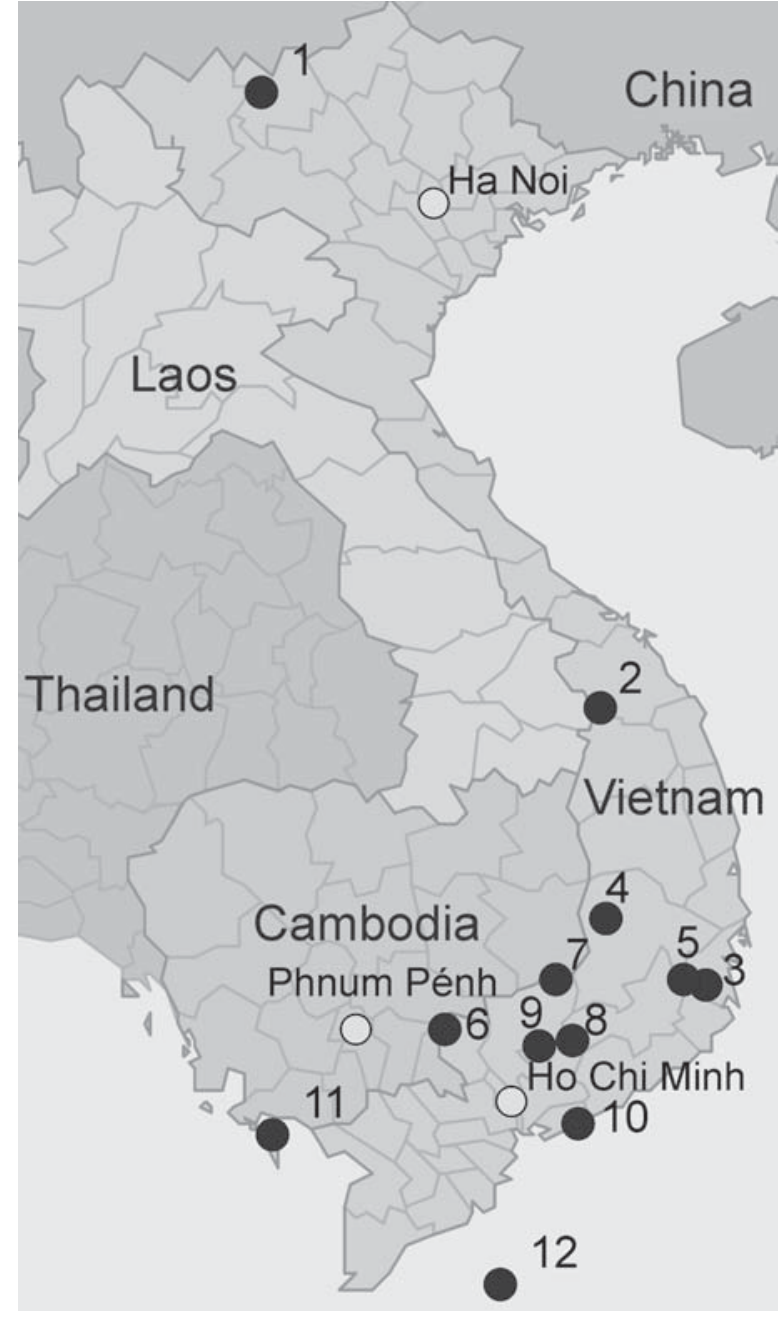

Figure 1. Map of localities. See APPENDIX I for detailed geographical information.

excluding the claw, and length of the ear from the intertragal notch to the crown were obtained in the field or were recorded by collector from field labels. Old adults, adults, and young adults (as defined by Musser \& Heaney, 1992) were grouped together as "adults," and their measurements were used to calculate standard descriptive statistics (mean, standard deviation, and observed range). The small sample size dictated that we combine the sexes in the analyses. Twenty cranial and dental characters were measured according to the scheme presented in Musser \& Newcomb (1983) and Musser et al. (2006). The scheme of the measurements is shown in Figure 2. Values for cranial and dental measurements were obtained by digital calipers or by an ocular micrometer of MBS-10 stereomicroscope to the nearest $0.05 \mathrm{~mm}$. Fourteen cranial indexes (ILB $=\mathrm{LB} / \mathrm{ONL}$, $\mathrm{IZB}=\mathrm{ZB} / \mathrm{ONL}, \mathrm{IIB}=\mathrm{IB} / \mathrm{BBC}, \mathrm{ILR}=\mathrm{LR} / \mathrm{ONL}, \mathrm{IBR} 1=$ $\mathrm{BBC} / \mathrm{BR}, \mathrm{IBR} 2=\mathrm{LR} / \mathrm{BR}, \mathrm{ILIF} 1=\mathrm{LIF} / \mathrm{LD}, \mathrm{ILIF} 2=$ $\mathrm{LIF} / \mathrm{BIF}, \mathrm{ILBP} 1=\mathrm{LBP} / \mathrm{LIF}, \mathrm{ILBP} 2=\mathrm{LBP} / \mathrm{BBP}, \mathrm{IPPL}=$ $\mathrm{PPL} /(\mathrm{LD}+\mathrm{LP}), \mathrm{IBZP} 1=\mathrm{ONL} / \mathrm{BZP}, \mathrm{IBZP} 2=\mathrm{BZP} / \mathrm{LD}$,
IMOL = CLM1-3/LIF) were additionally calculated. The mean and standard deviation (SD) of the skull measurements and indexes are shown in APPENDIX III. The statistical analysis was performed using Statistica 6.0 (StatSoft, 2001). A preliminary analysis of the measurements and indexes was performed by applying the t-test. The variables shown to be the most relevant for species discrimination were selected for stepwise discriminant analysis.

DNA extraction, purification and PCR/sequencing procedures. Small pieces $(0.2-0.3 \mathrm{~g})$ of muscle and liver were sampled for molecular genetic analysis and preserved by molecular-grade $96 \%$ ethanol just after the animals were sacrificed. Total genomic DNA was extracted from the samples using a routine phenol/ chloroform/proteinase K protocol (Kocher et al., 1989; Sambrook et al., 1989), and it was further purified by twofold ethanol precipitation or using a DNA Purification Kit (Fermentas). A 1.3-kb fragment of mitochondrial DNA containing the full cytochrome $b$ (cyt $b$ ) gene was amplified with a pair of universal primers: H15915R (5'-GGAATTCATCTCTCCGGTTTACAAGAC-3') (Irwin et al., 1991) and Cyt bRglu2L (5'CAGCATTTAACTGTGACTAATGAC-3') (Robins et al., 2007). Another pair of primers was used to obtain a 750-bp fragment of the cytochrome $c$ oxidase subunit I (COI) gene, COI BatL5310 (5'-CCTACTCRGCCATTTTACCTATG-3') and COI R6036R (5'-ACTTCTGGGTGTCCAAAGAATCA-3') (Robins et al., 2007). PCR was carried out in a 30-50 $\mu \mathrm{l}$ volume containing 2.5-3 mkl 10x standard PCR buffer (Fermentas), $50 \mathrm{mM}$ of each dNTP, $2 \mathrm{mM} \mathrm{MgCl}, 10-12$ pmole of each primer, 1 unit of Taq DNA polymerase (Fermentas) and $0.5 \mathrm{ml}(20-50 \mathrm{ng})$ of total DNA template per tube in a Tercik (DNK-Tehnologia) thermocycler. A universal PCR protocol was used for amplification of all fragments: initial denaturation for 1 min $30 \mathrm{sec}$ at $95^{\circ} \mathrm{C}$, denaturation for $30 \mathrm{sec}$ at $95^{\circ} \mathrm{C}$, annealing for $1 \mathrm{~min}$ at $52^{\circ} \mathrm{C}$, and elongation for $30 \mathrm{sec}$ at $72^{\circ} \mathrm{C}$ followed by terminal elongation for $2 \mathrm{~min}$ at $72^{\circ} \mathrm{C}$. The PCR products were purified with a DNA Purification Kit (Fermentas). Double-stranded DNA products were directly sequenced in both directions with an Applied Biosystems 3130 Genetic Analyzers using the ABI PRISM BigDye Terminator Cycle Sequencing Ready Reaction Kit. All the sequences obtained (Table 1) were submitted to GenBank and some of them were also uploaded in the BOLD database (project name "Indochinese Muridae", ICMBA).

Data analyses. All cyt $b$ sequences for Niviventer spp. available in GenBank as of the 31st of January 2010, including 35 sequences described in Jing et al. (2007), Lecompte et al. (2008) and Jansa et al. (2006), were evaluated to obtain a total of 109 sequences representing 18 taxa (Table 1). Three out-species, including Rattus rattus (AB033702), Leopoldamys sabanus (GU457019), and Mus musculus (J011420), were used as outgroups. 

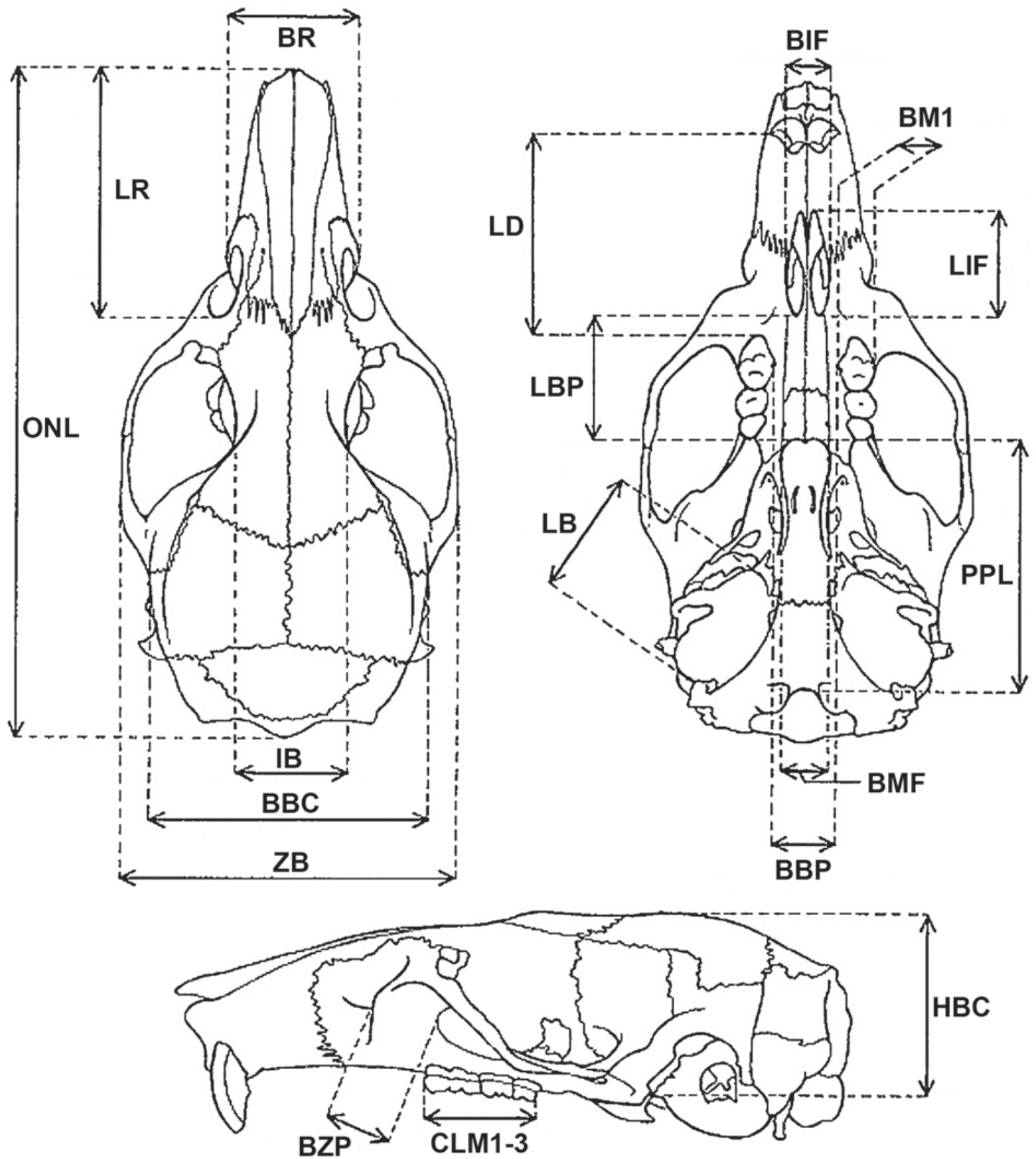

Figure 2. Scheme of cranial measurements. Occipitonasal length, or the greatest length of the skull (ONL), zygomatic breadth (ZB), interorbital breadth (IB), length of rostrum (LR), breadth of rostrum (BR), breadth of braincase (BBC), height of braincase (HBC), breadth of zygomatic plate (BZP), length of diastema (LD), length of incisive foramina (LIF), breadth of incisive foramina (BIF), palatal length (LBP) (palatal bridge), breadth across palate at first molars (BBP), postpalatal length (PPL), breadth of mesopterygoid fossa (BMF), length of bulla (LB), crown length of maxillary molar row (CLM1-3), crown length of mandibular row (CLm1-3, not shown), crown breadth of $\mathrm{M}^{1}$ (BM1), crown breadth of $\mathrm{m}_{1}$ (Bm1, not shown). Cranial measurements according to Musser \& Newcomb (1983) and Musser et al. (2006).

All sequences were aligned using BioEdit (Hall, 1999) and Clustal W (incorporated into BioEdit and MEGA 4.0) software and checked manually. Basic sequences parameters (variable sites, parsimony infor- mative sites, base composition biases, nucleotide frequencies and nucleotide substitution tables), inter- and intrapopulation divergence evaluation and tree constructions using maximal parsimony (MP), minimal 
Table 1. The list of specimens used for genetic analysis (cyt $b$ gene only). See APPENDIX I for detailed geographical information.

\begin{tabular}{|c|c|c|c|c|}
\hline Species & Locality & GenBank ID (cyt $b$ ) & $n$ & Source \\
\hline N. fulvescens & Hoang Lien NP, Vietnam & $\begin{array}{l}\text { FJ665443, 47-50, 62-63, } \\
\text { 65; GU456700-705 }\end{array}$ & 13 & \multirow{11}{*}{ Original data } \\
\hline \multirow{3}{*}{ N. huang } & Nam Cat Tien NP, Vietnam & $\begin{array}{l}\text { FJ665439-40, 66; } \\
\text { GU456971 }\end{array}$ & 4 & \\
\hline & Lo Go Xa Mat NR, Vietnam & GU456988-92 & 5 & \\
\hline & Bi Dup - Nui Ba NP, Vietnam & GU4569772-76 & 5 & \\
\hline$N$. niviventer & Hoang Lien NP, Vietnam & FJ665464; GU456993-99 & 8 & \\
\hline \multirow{2}{*}{ N. bukit } & Nam Cat Tien NP, Vietnam & $\begin{array}{l}\text { FJ665441-42, 44-46, 51-56, } \\
59-61\end{array}$ & 14 & \\
\hline & Bi Dup - Nui Ba NP, Vietnam & $\begin{array}{l}\text { FJ665436, 38; GU456977- } \\
87\end{array}$ & 13 & \\
\hline N. confucianus & Hoang Lien NP, Vietnam & $\begin{array}{l}\text { GU457017-18; FJ665457- } \\
58\end{array}$ & 4 & \\
\hline N. tenaster & Bi Dup - Nui Ba NP, Vietnam & GU457010 & 1 & \\
\hline N. langbianis & Bi Dup - Nui Ba NP, Vietnam & $\begin{array}{l}\text { FJ665434-35, 37; } \\
\text { GU457006-8 }\end{array}$ & 6 & \\
\hline N. cremoriventer & $\begin{array}{l}\text { Vinh Cuu NR (= Ma Da), } \\
\text { Vietnam }\end{array}$ & GU827392 & 1 & \\
\hline N. andersoni & $\begin{array}{l}\text { Shanxi and Yunnan provinces, } \\
\text { China }\end{array}$ & EF053001-03 & 3 & \multirow{5}{*}{ Jing et al., 2007} \\
\hline N. brahma & Yunnan Province, China & EF053010-11 & 2 & \\
\hline N. confucianus & $\begin{array}{l}\text { Shanxi and Yunnan provinces, } \\
\text { China }\end{array}$ & EF053020-23 & 4 & \\
\hline $\begin{array}{l}N . \text { coninga } \\
(=N . \text { coxinga })\end{array}$ & Yunlin, Gaoxiong, Taiwan & EF053024-26 & 3 & \\
\hline \multirow{2}{*}{$N$. niviventer } & Yunnan Province, China & EF053030-32 & 3 & \\
\hline & Hoa Binh Province, Vietnam & AM408344 & 1 & $\begin{array}{l}\text { Lecompte } \text { et al., } \\
2008\end{array}$ \\
\hline N. culturatus & Nantou, Gaoxiong, Taiwan & EF053027-29 & 3 & \multirow{3}{*}{ Jing et al., 2007} \\
\hline N. eha & Yunnan Province, China & EF053018-19 & 2 & \\
\hline \multirow{2}{*}{ N. excelsior } & Yunnan Province, China & EF053004-09 & 6 & \\
\hline & China Province, & DQ191482 & 1 & Jansa et al., 2006 \\
\hline N. fulvescens & Yunnan Province, China & EF053012-17 & 6 & Jing et al., 2007 \\
\hline N. rapit & Borneo & DQ191483 & 1 & Jansa et al., 2006 \\
\hline Rattus rattus & & AB033702 & 1 & \\
\hline Mus musculus & & J01420 & 1 & \\
\hline Leopoldamys sabanus & Lo Go Xa Mat NR, Vietnam & GU457019 & 1 & Original data \\
\hline
\end{tabular}

evolution (ME), and neighbor-joining (NJ) algorithms were obtained with MEGA 4.0 (Tamura et al., 2007). A maximal likelihood (ML) algorithm was realized by DNAMLK version 3.5c (Felsenstein, 1981) distributed as a BioEdit component. The trees that were constructed were visualized directly by MEGA 4.0 or, for MLtrees, by applying the TreeView program (Page, 1996).

Species attribution and delimitation. All the individuals were preliminarily identified in the field based on external morphology by consultation of field identification manuals (Van Peenen, 1969; Lunde \& Nguyen Truong Son, 2001), and the specific traits of skulls that are described in Corbet \& Hill (1992) were investigated later in the laboratory under a stereomicroscope to compare with the original species descriptions (Musser, 1973, 1981; Musser \& Carleton, 1993, 2005; Osgood, 1932; Stephen \& Rudolf, 2007). Our species identification was based mainly on external character- 


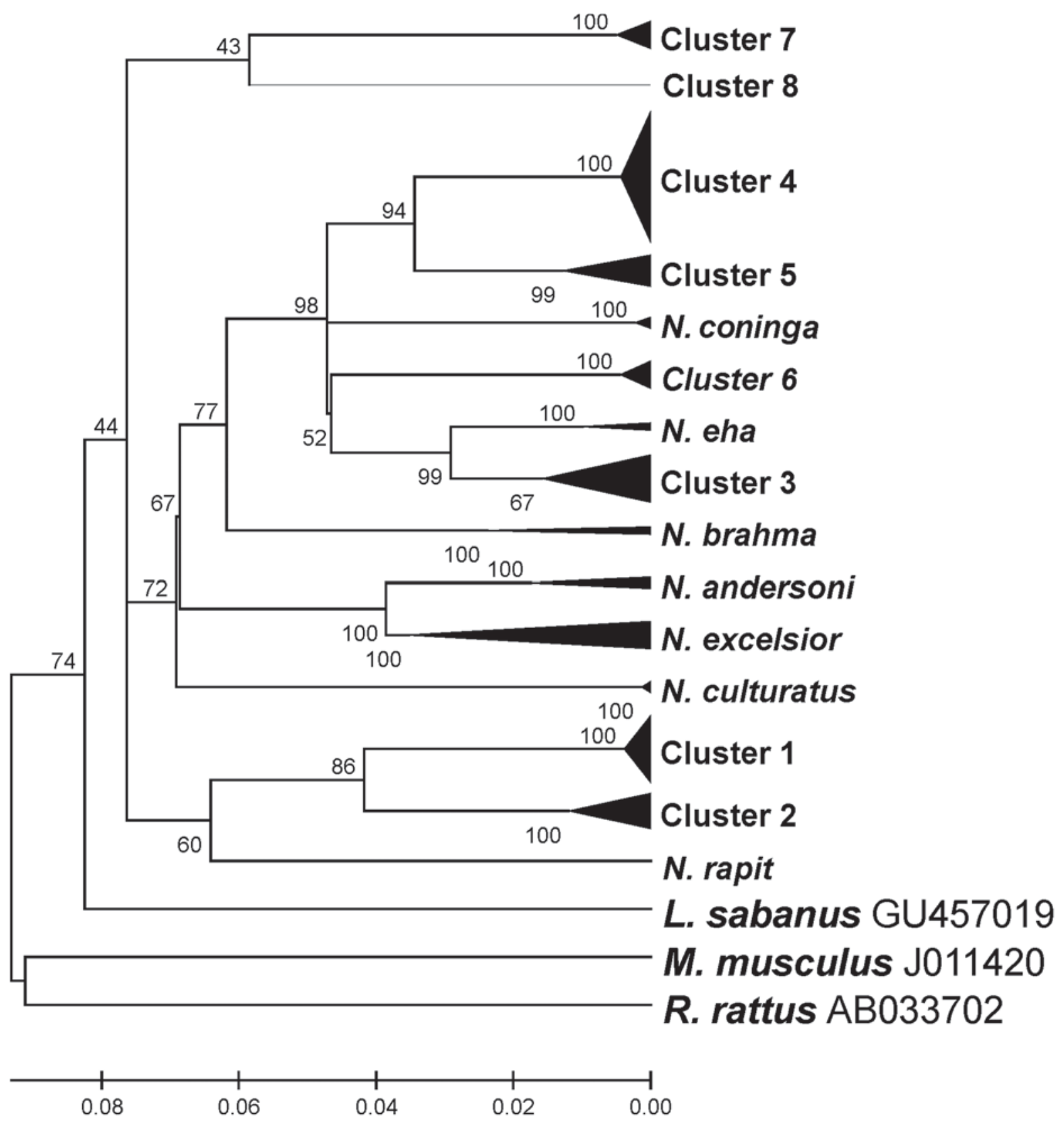

Figure 3. Phylogenetic relationships within Niviventer species inhabiting Indochina and Sunda Shelf region as inferred from cyt $b$ gene sequences; generalized tree. Distal branches are shown compressed. Bootstrap values (ME/NJ/MP) are shown above branches. Intergroup divergence scale is at the bottom.

istics and skull morphology. Nevertheless, the final species attributions and the geographical distributions of the haplotypes were tested using the BOLD interactive species diagnosis system (Hebert et al., 2003; Savolainen et al., 2005) by comparing our data with a variety of COI sequences deposited in BOLD and presented by Pagés et al. (2010), along with an original phylogenetic pattern based on estimation of the genetic divergence of cyt $b$ (Balakirev \& Rozhnov, 2010).

\section{Results}

Phylogenetic analysis. Of 1143 cyt $b$ gene nucleotide sites, 443 were variable and 364 parsimoniously informative (taking into account exterior groups, 489 and 379, were variable and parsimoniously informative, respectively). In total, 15 well-defined genetic lineages could be distinguished among the 109 currently available cyt $b$ sequences; among them, 8 were present 
among the Vietnamese fauna. All of the obtained trees (MP, ME, NJ, and ML) had similar topologies and differed only in the level of support for some nodes; this allowed us to present a generalized tree based on the NJ/ME/MP algorithms (Fig. 3). These 15 species-level genetic lineages were preliminary designated as forms $1-8$, which is consistent with the branching mode obtained by investigation of the COI gene phylogeny but with generally higher topological resolution. The species attributions of these lineages are discussed in detail below. The level of intergroup divergence $(d$, T3P) varied from 0.069 to 0.165 between $N$. langbianis and $N$. confucianus with the level of intergroup divergence for most species being quite low (0.002-0.027, on an average 0.0187 ). Based on the tree topology and interspecies divergence level, some phylogenetic lineages could be distinguished with in the genus Niviventer, see Balakirev \& Rozhnov (2010) for details. At least three additional specific monophyletic clusters comprising two species, such as $N$. andersoni and $N$. excelsior from southwestern China, can be clearly separated, and each is more basal than the "andersoni" division that is currently generally accepted. The first is a cluster comprising two species (clusters 1 and 2, Fig. 3), N. fulvescens and $N$. huang (see discussion below), together with one of Bornean species, $N$. rapit. Two other species (clusters 7 and 8, Fig. 3), namely $N$. langbianis and $N$. cremoriventer, also constitute an independent basal clade. Ten other species constitute a monophyletic clade that can be separated from three other subclades along the "andersoni" division. The Taiwanese species $N$. culturatus and another one, namely N. brahma from western Indochina (NE India, N Burma and SW China), which form their own well-separate branches and a large complex group comprising six other species. $N$. coninga (= coxingi sensu Jing et al., 2007, but see Musser \& Carleton, 2005), N. eha, and clusters 3-6, which are treated here as $N$. niviventer, $N$. confucianus, $N$. tenaster and $N$. bukit (see discussion below), are closely related species. The latter four taxa may be apparently regarded as the superspecies, $N$. niviventer. Thus, based on the fact that the only division currently accepted within the genus Niviventer ("andersoni" division) does not even construct the most basal clade, these additional phylogenetic lineages are worth to be equally regarded as separate divisions. The first may be named as "fulvescens" division; the other should be nominated as "langbianis" division. The third division, combining $N$. coninga, $N$. eha, $N$. niviventer, $N$. confucianus, $N$. tenaster and $N$. bukit is worth being also separated under the name "niviventer-confucianus" division. The lineages which treat by Jing et al. (2007) as N. culturatus and $N$. brahma may also be elevated to division status.

Species diagnostic based on external and cranial characters

The general skull traits are presented in Figures 512 , and the cranial measurements are summarized in
APPENDIX III. The standard set of skull measurements, particularly the measurements characterizing the general size of the skull, was found to be of little value for species delimitation because of the considerable overlap among the values. In our sample, LR, BR, LD, LIF, BZP, LBP, BBP, PPL, and LB were found to be more informative. A series of indexes was calculated based on the ratio of each measurement to the ONL (for longitudinal measurements) or to the $\mathrm{BBC}$ (for transversal measurements). The indexes were found to be sufficient for clear species separation based on craniological characters. The following 14 indexes were tested for species discrimination: ILB, IZB, IIB, ILR, IBR1, IBR2, ILIF1, ILIF2, ILBP1, ILBP2, IPPL, IBZP1, IBZP2, IMOL (see Materials and methods for details). Three of these were discarded due to a lack of interspecific differences (IPPL, ILIF2 and IMOL), and the others were found to be species-specific for the delimitation of some pairs and groups of species. Thus, these indices were used as variables in the discriminant analysis.

The discriminant analysis was performed using an inverse stepwise method with successive reduction of the complexity from an 11-1 to a 7-parameter model that was based on IBZP, ILBP, ILB, IZB, ILR, IBR1, and IIB. The last model was shown to express the highest discriminant function value (Wilk's Lambda 0.01599 ; $\mathrm{F}(42.228)=7.7025, \mathrm{p}<0.0000$, see APPENDIX IV). Nevertheless, in spite of the overall higher level of reliability, the model failed to achieve $100 \%$ discrimination of species in a general data array (7 species were included, and $N$. cremoriventer was represented by only one specimen in this analysis). Only $N$. confucianus and $N$. langbianis were shown to be correctly discriminated from all other species $100 \%$ of the time; coefficient of discrimination ranged from 83.33 to $90.9 \%$ for the other species. $N$. fulvescens was found to be most complicated case; the coefficient of discrimination was calculated by the 7-parameter model as only $62 \%$ for this species, which was most frequently misidentified as $N$. niviventer. In this situation, a conceptual parameter such as ILB, which was excluded from the final analysis, is necessary. ILB, which characterizes the size of the auditory bulla, is a key character for $N$. fulvescens and $N$. huang delimitation, but the lack of any significant difference in this measurement among five other species leads to a general decrease in the significance level of the model. If ILB is included in the model, $N$. fulvescens is accurately segregated, and the accuracy of segregation of the "large-bullae species" is diminished.

When this restriction was not taken in to consideration, no more than one individual of every species failed to be correctly identified by the final 7-parameter model, and the misidentified individuals were aberrant or young animals. Under these conditions, the model achieves complete separation only for sympatrically distributed species (such as $N$. bukit and $N$. huang; $N$. bukit, $N$. langbianis and $N$. tenaster; $N$. fulvescens, $N$. niviventer and $N$. confucianus). 


\section{Discussion}

According to Musser \& Carleton (2005), there are only three Niviventer species recorded in Vietnam; $N$. fulvescens, $N$. confucianus and $N$. langbianis. An additional species, $N$. tenaster, was listed for Vietnam in latest reviews (Lunde \& Nguyen Truong Son, 2001; Dang Ngoc Can et al., 2008; Francis, 2008). Therefore, based on the generally accepted taxonomic model, three to four species-clades are predicted to exist in the fauna of the country (but see Kuznetsov, 2006, who listed up to seven species in Vietnam - fulvescens, niviventer, bukit, confucianus, tenaster, langbianis, and cremoriventer). Nevertheless, six morphologically wellseparated morphs have been revealed based on our preliminary morphological investigations. After processing of the genetic data (Fig. 3), we could clearly recognize at least eight Niviventer species within the fauna of Vietnam, namely huang, fulvescens, niviventer, bukit, confucianus, tenaster, langbianis and cremoriventer. Their morphological diagnoses and distribution ranges are given in the species profiles (see below).

The species assignment of many Indochinese and Sundaic forms has long been debated, resulting in uncertainty in their taxonomic rank. The main question in the Niviventer taxonomy is to determine what of these form/species should actually be identified as $N$. fulvescens. A comparative analysis of Indochinese, Sundaic and Thailand Niviventer performed by Abe (1983) supported the viewpoint of Osgood (1932) and Ellerman (1949) that $N$. bukit should be a morph of $N$. fulvescens. At the same time, it was demonstrated by a morphological investigation of Musser and Lunde (cited by Musser \& Carleton (2005) with a redirection to unpublished data) that $N$. fulvescens in fact represented a cluster of closely related species also comprising $N$. hinpoon from Thailand and N. fraternus from Sumatra. This last statement described a completely new phylogenetic pattern and had to be verified by independent morphological and genetic analyses. It should also be noted that based on the unpublished data of Patton (J.L. Patton, in litt., 2000; cited after Musser \& Carleton, 2005), the analysis of cyt $b$ showed that $N$. fulvescens was phylogenetically closer to the clade comprising $N$. tenaster, $N$. coninga, $N$. confucianus and $N$. culturatus than to $N$. langbianis. This point is generally consistent with our data (Fig. 3, Tab. 2). It seems that both Patton (sited after Musser \& Carleton, 2005) and Jing et al. (2007) treated exactly the same species, match for form 3 in our study, as $N$. fulvescens. This opinion is mistaken because the typical $N$. fulvescens is a small-bullae species according to the detailed morphological descriptions and taxonomic review presented by Musser (1981) and Musser \& Newcomb (1983). Our results confirm that the typical small-bullae species - N. fulvescens, together with its closest relative $N$. huang, form an independent phylogenetic lineage that is even closer to
$N$. langbianis than all the other large-bullae Niviventer species. These large-bullae species, viz. N. confucianus, $N$. tenaster, $N$. bukit, Taiwanese endemic $N$. coninga and Chinese $N$. eha together with $N$. niviventer, but not $N$. fulvescens (!), actually represent a cluster of closely related species that is topologically difficult to resolve.

With respect to the species composition and status of the niviventer-confucianus superspecies, it is important to stress that, as it can be seen from Figure 3 and Table 2, N. bukit is equally separated within the niviventer-confucianus group. Based on our analysis, $N$. tenaster is a species that is quite distinct from $N$. confucianus and $N$. niviventer, and we support its full species rank. Therefore, it would be consistent to also classify $N$. bukit as a full species. Otherwise, we should admit the occurrence and wide distribution of the divergent dwarf morph of $N$. confucianus in Southern Indochina, which has never been proposed before.

As mentioned above, four Vietnamese species, viz. $N$. niviventer, $N$. bukit, $N$. confucianus and $N$. tenaster, have larger bullae and form a monophyletic cluster (Fig. 3, clades 3-6). The species are not particularly genetically divergent (interspecies d's are 0.069-0.096, so in general the group can be regarded as a superspecies sensu E. Mayr (Mayr, 1963). These species have morphologically perceptible traits and can be geographically subdivided into two sympatric pairs $(N$. confucianus $-N$. niviventer and $N$. tenaster $-N$. bukit). At the same time, they can be morphologically subdivided into a pair of larger species $N$. confucianus $-N$. tenaster and a pair of smaller ones $N$. niviventer $-N$. bukit.

Close relationships of these species were hitherto discussed (Musser, 1981; Corbet \& Hill, 1992; Musser $\&$ Carleton, 1993, 2005) on the basis of morphological criteria, and the results of our genetic analysis are in full agreement with such the conclusion. However, this group (or superspecies) cannot be matched to the "niviventer complex" sensu Musser (1981) because it also includes $N$. fulvescens sensu lato (including $N$. huang), which forms a well-defined independent clade (Fig. 3).

In addition to the two groups mentioned above, another group consisting of two species can be morphologically separated corresponding to the phylogenetic subdivision (Fig. 3, clades 7 and 8). The first member of this group is $N$. langbianis, the species considered to be the only representative of the genus Niviventer in the region that bears a unicolored dark tail (Musser, 1973, 1981; Corbet \& Hill, 1993; Musser \& Carleton, 2005; Francis, 2008). Here, we have recognized another taxon (form 8) from Southern Vietnam - N. cremoriventer that also presents a unicolored dark tail. Therefore, at least two related Niviventer species bearing a unicolored dark tail inhabit the area northward of the Isthmus of Kra. 


\begin{tabular}{|c|c|c|c|c|c|c|c|c|c|c|c|c|c|c|c|}
\hline 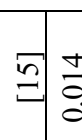 & 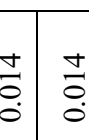 & $\begin{array}{l} \pm \\
\vdots \\
0 \\
0\end{array}$ & $\begin{array}{l}n \\
\vdots \\
0 \\
0\end{array}$ & $\stackrel{5}{0}$ & $\underset{\Xi}{0}$ & $\begin{array}{l}\Delta \\
\vdots \\
0\end{array}$ & $\begin{array}{l}\mathfrak{a} \\
\Xi \\
0\end{array}$ & $\begin{array}{l}0 \\
0 \\
0\end{array}$ & $\begin{array}{l}0 \\
0 \\
0\end{array}$ & $\begin{array}{l}n \\
0 \\
0\end{array}$ & 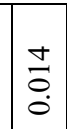 & $\begin{array}{l}n \\
0 \\
0 \\
0\end{array}$ & $\frac{n}{0}$ & $\begin{array}{l}\Delta \\
\\
0\end{array}$ & ' \\
\hline$\exists \frac{a}{a}$ & \begin{tabular}{l|l}
$m$ & $\stackrel{m}{a}$ \\
& $\stackrel{0}{0}$ \\
$\dot{0}$
\end{tabular} & \begin{tabular}{l|l} 
\pm \\
$\vdots$ \\
$\vdots$ \\
0
\end{tabular} & $\begin{array}{l}n \\
\vdots \\
0 \\
0\end{array}$ & $\frac{\Delta}{0}$ & $\frac{a}{a}$ & $\begin{array}{l}m \\
0 \\
0\end{array}$ & $\mid \begin{array}{l}m \\
0 \\
0 \\
0\end{array}$ & $\stackrel{1}{0}$ & $\overrightarrow{\vec{a}}$ & $\stackrel{m}{0}$ & $\stackrel{m}{a}$ & $\begin{array}{l}\vec{a} \\
0 \\
0\end{array}$ & $\bar{\Xi}$ & $\stackrel{\infty}{0}$ & $\stackrel{\Xi}{=}$ \\
\hline 긍 & \begin{tabular}{l|l}
$\frac{m}{7}$ & $m$ \\
0 & 0 \\
0 & 0
\end{tabular} & \begin{tabular}{l|l}
$m$ \\
$\vdots$ \\
0 \\
0
\end{tabular} & $\begin{array}{l}m \\
0 \\
0 \\
0\end{array}$ & $\stackrel{\Delta}{\Delta}$ & $\begin{array}{l}0 \\
0 \\
0\end{array}$ & $\begin{array}{l}n \\
0 \\
0 \\
0\end{array}$ & $\mid$\begin{tabular}{l}
0 \\
\hdashline \\
0 \\
0
\end{tabular} & $\stackrel{m}{0}$ & $\stackrel{1}{\circ}$ & $\stackrel{1}{\square}$ & $\stackrel{T}{\square}$ & $\begin{array}{l}8 \\
8 \\
0 \\
0\end{array}$ & $\stackrel{\infty}{\stackrel{0}{0}}$ & $\frac{\vec{m}}{-}$ & $\frac{n}{m}$ \\
\hline$\exists \stackrel{\Xi}{\exists}$ & \begin{tabular}{l|l}
$\frac{n}{2}$ & $m$ \\
0 & 0 \\
0 & 0
\end{tabular} & \begin{tabular}{l|l}
$m$ \\
$\vdots$ \\
0 \\
0
\end{tabular} & $\begin{array}{l}\mathfrak{a} \\
\vdots \\
0\end{array}$ & $\frac{1}{0}$ & $\frac{O}{0}$ & $\begin{array}{l}\Delta \\
0 \\
0 \\
0\end{array}$ & $\mid$\begin{tabular}{l}
$\mathcal{O}$ \\
\hdashline \\
0 \\
0
\end{tabular} & $\stackrel{m}{0}$ & $\stackrel{1}{0}$ & $\stackrel{m}{0}$ & $\stackrel{1}{\circ}$ & 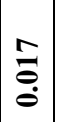 & $\begin{array}{l}\tilde{O} \\
\stackrel{0}{0} \\
0\end{array}$ & 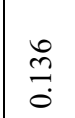 & $\frac{9}{9}$ \\
\hline$\exists \Xi$ & $\begin{array}{ccc}\stackrel{m}{\square} & \stackrel{0}{0} \\
0 & 0 \\
0\end{array}$ & $\begin{array}{l}m \\
\frac{m}{0} \\
0 \\
0\end{array}$ & $\stackrel{m}{0}$ & $\stackrel{n}{0}$ & $\begin{array}{l}0 \\
0 \\
0 \\
0\end{array}$ & $\stackrel{m}{a}$ & $\mid \begin{array}{l}m \\
0 \\
0 \\
0\end{array}$ & $\stackrel{\Delta}{\ddot{0}}$ & $\stackrel{m}{0}$ & $\begin{array}{l}\overrightarrow{0} \\
0 \\
0\end{array}$ & ' & $\stackrel{n}{m}$ & $\stackrel{n}{\cong}$ & $\begin{array}{l}n \\
n \\
0\end{array}$ & $\overrightarrow{\widetilde{I}}$ \\
\hline 의 & $\begin{array}{ll}\stackrel{1}{0} & \overline{0} \\
0 & 0 \\
0 & 0\end{array}$ & \begin{tabular}{l|l}
$\vec{z}$ \\
$\overrightarrow{0}$ \\
0 \\
0
\end{tabular} & $\stackrel{m}{0}$ & $\stackrel{1}{0}$ & $\begin{array}{l}n \\
0 \\
0 \\
0\end{array}$ & $\frac{m}{0}$ & $\mid$\begin{tabular}{l}
3 \\
\hdashline \\
0 \\
0
\end{tabular} & $\stackrel{m}{0}$ & $\stackrel{1}{\circ}$ & $\stackrel{\check{\Xi}}{\stackrel{0}{0}}$ & $\mid \begin{array}{l}\hat{m} \\
0 \\
0\end{array}$ & $\frac{\vec{J}}{\dot{0}}$ & $\frac{0}{\stackrel{0}{0}}$ & $\frac{g}{\stackrel{g}{0}}$ & $\frac{\tilde{n}}{0}$ \\
\hline a & 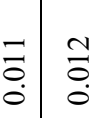 & $\begin{array}{l}\frac{1}{2} \\
\vdots \\
0 \\
0\end{array}$ & $\stackrel{a}{a}$ & $\frac{1}{0}$ & $\frac{\pi}{0}$ & $\frac{n}{0}$ & $=$ & $\hat{o}$ & $\stackrel{\widehat{O}}{\stackrel{0}{0}}$ & $\frac{\vec{J}}{\dot{0}}$ & $\mid \begin{array}{l}n \\
\frac{n}{0} \\
0\end{array}$ & $\frac{\vec{n}}{0}$ & $\frac{0}{9}$ & $\frac{\vec{J}}{0}$ & $\frac{4}{\stackrel{5}{0}}$ \\
\hline$\infty$ & 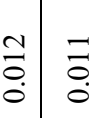 & $\begin{array}{l}\vec{z} \\
\overrightarrow{0} \\
0 \\
0\end{array}$ & $\frac{1}{0}$ & $\vec{a}$ & $\begin{array}{l}0 \\
0 \\
0 \\
0\end{array}$ & $\vec{z}$ & $\vec{a}$ & $\stackrel{\oplus}{\oplus}$ & $\stackrel{\hat{s}}{0}$ & $\stackrel{n}{\stackrel{n}{0}}$ & $\mid$\begin{tabular}{l|}
0 \\
0 \\
0 \\
0
\end{tabular} & $\frac{4}{2}$ & $\frac{0}{\stackrel{0}{0}}$ & $\begin{array}{l}\overrightarrow{6} \\
\stackrel{0}{0}\end{array}$ & $\begin{array}{l}\vec{\sigma} \\
\overrightarrow{0}\end{array}$ \\
\hline 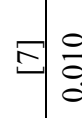 & 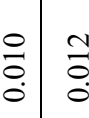 & 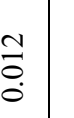 & $\stackrel{ }{0}$ & $\frac{1}{0}$ & $\begin{array}{l}0 \\
0 \\
0 \\
0\end{array}$ & $\vec{\sigma}$ & $\mid \begin{array}{l}\hat{y} \\
\dot{S}\end{array}$ & $\stackrel{f}{\stackrel{f}{0}}$ & $\frac{8}{1}$ & $\frac{n}{0}$ & $\mid \begin{array}{l}\vec{n} \\
\overrightarrow{0}\end{array}$ & $\frac{g}{\dot{I}}$ & $\frac{\vec{n}}{0}$ & $\frac{8}{8}$ & $\stackrel{\infty}{=}$ \\
\hline 의 & 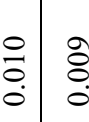 & 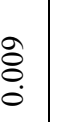 & $\stackrel{0}{0}$ & $\stackrel{0}{0}$ & $\begin{array}{l}\infty \\
0 \\
0 \\
0\end{array}$ & $\stackrel{o}{\overrightarrow{0}}$ & $\underset{I}{\tilde{I}}$ & $\frac{8}{0}$ & $\frac{\nexists}{\stackrel{ \pm}{0}}$ & $\frac{0}{\stackrel{0}{0}}$ & $\frac{q}{\stackrel{g}{0}}$ & $\frac{\pi}{0}$ & $\frac{n}{0}$ & $\frac{n}{n}$ & $\frac{+}{m}$ \\
\hline$n$ & $\begin{array}{lll}0 & \stackrel{0}{0} \\
\vdots & 0 \\
0 & 0\end{array}$ & ठे. & $\begin{array}{l}\text { } \\
\text {. }\end{array}$ & $\begin{array}{l}0 \\
0 \\
0 \\
0\end{array}$ & 苈 & $\begin{array}{l}\infty \\
\infty \\
0 \\
0 \\
0\end{array}$ & $\mid$\begin{tabular}{l}
$O$ \\
\hdashline \\
0
\end{tabular} & $\frac{n}{0}$ & $\frac{\mathcal{I}}{0}$ & $\frac{\tilde{n}}{0}$ & $\mid \begin{array}{l}3 \\
0 \\
0 \\
0\end{array}$ & $\frac{\mathcal{Y}}{\stackrel{0}{0}}$ & $\frac{a}{3}$ & $\frac{n}{i n}$ & $\stackrel{2}{\cong}$ \\
\hline 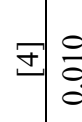 & $\begin{array}{lll}\circ & \circ \\
\circ & 0 \\
\circ & 0\end{array}$ & \begin{tabular}{l|l|}
0 \\
0 \\
0 \\
0
\end{tabular} & $\stackrel{0}{0}$ & $\stackrel{\hat{\theta}}{0}$ & $\begin{array}{l}0 \\
8 \\
0 \\
0\end{array}$ & $\hat{o}$ & $\frac{\hat{m}}{\overrightarrow{0}}$ & $\frac{\mathcal{I}}{0}$ & $\frac{0}{\stackrel{0}{0}}$ & $\stackrel{n}{\stackrel{n}{0}}$ & 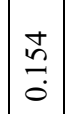 & $\frac{\infty}{\dot{d}}$ & $\frac{R}{2}$ & 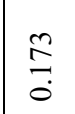 & $\frac{\tilde{n}}{0}$ \\
\hline 9 & $\stackrel{\circ}{\circ} \stackrel{0}{\circ} \stackrel{0}{\circ}$ & $\begin{array}{l}0 \\
\frac{0}{0} \\
0\end{array}$ & $\stackrel{\Xi}{0}$ & $\frac{\tilde{\sigma}}{0}$ & $\begin{array}{l}\hat{\infty} \\
0 \\
0\end{array}$ & $\begin{array}{l}0 \\
\circ \\
0 \\
0\end{array}$ & $\mid \begin{array}{l}9 \\
0\end{array}$ & $\underset{\Xi}{\vec{J}}$ & $\stackrel{\text { ले }}{\circ}$ & $\frac{\text { I }}{0}$ & $\mid \begin{array}{c}0 \\
\stackrel{n}{0} \\
\stackrel{0}{0}\end{array}$ & 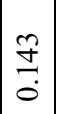 & $\frac{\stackrel{0}{n}}{\stackrel{0}{0}}$ & $\frac{8}{0}$ & 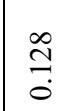 \\
\hline 교 & 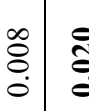 & 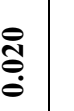 & $\begin{array}{l}n \\
\hat{o}\end{array}$ & $\hat{o}$ & $\begin{array}{l}2 \\
\ddot{0} \\
0 \\
0\end{array}$ & $\mid \begin{array}{l}0 \\
\infty \\
0 \\
0\end{array}$ & $\overrightarrow{\vec{I}}$ & $\stackrel{0}{\stackrel{0}{0}}$ & $\stackrel{\infty}{\stackrel{\infty}{0}}$ & 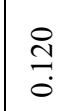 & $\underset{q}{\stackrel{f}{0}}$ & $\frac{8}{3}$ & $\frac{9}{0}$ & \begin{tabular}{l}
$n$ \\
\hdashline \\
0
\end{tabular} & $\stackrel{\infty}{\cong}$ \\
\hline & 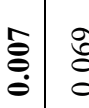 & 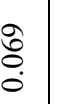 & 奋 & 足 & ô. & o. & $\overrightarrow{\widetilde{I}}$ & $\begin{array}{l}0 \\
\stackrel{0}{0} \\
0\end{array}$ & $\frac{\hat{m}}{0}$ & $\stackrel{m}{\stackrel{0}{0}}$ & $\underset{\stackrel{q}{q}}{\stackrel{q}{0}}$ & $\frac{8}{3}$ & $\frac{n}{\infty}$ & $\frac{n}{0}$ & $\stackrel{2}{ \pm}$ \\
\hline & 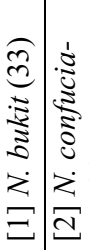 & $\widehat{3}$ & 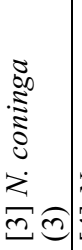 & 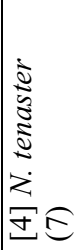 & 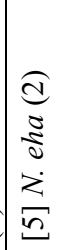 & 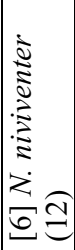 & 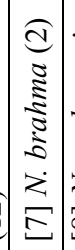 & 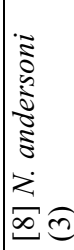 & 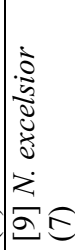 & 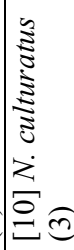 & $\mid \begin{array}{c}\Xi \\
\vec{\Xi} \\
\vec{z} \\
\vdots \\
z \\
\Xi \\
\Xi\end{array}$ & 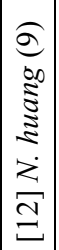 & 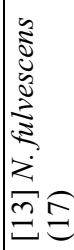 & 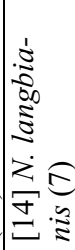 & 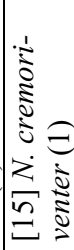 \\
\hline
\end{tabular}



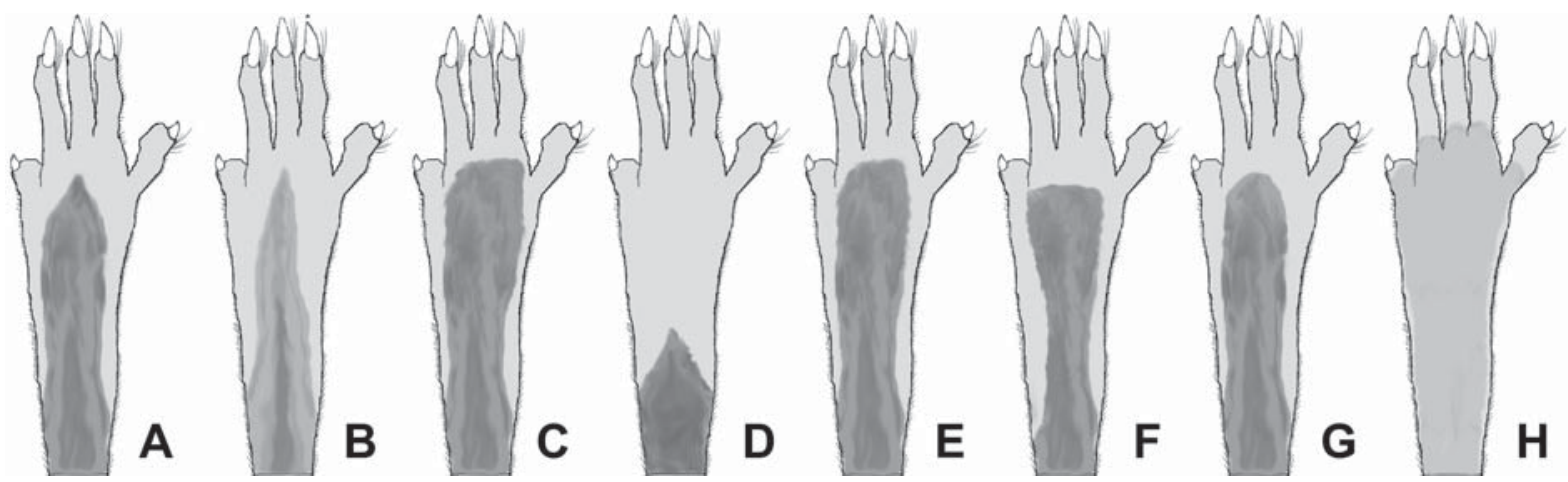

Figure 4. Feet coloration pattern in Niviventer spp. A $-N$. fulvescens; B $-N$. huang; C $-N$. niviventer; D $-N$. bukit; $\mathrm{E}-N$. confucianus; F - N. tenaster; $\mathrm{G}-N$. langbianis; $\mathrm{H}-$ N. cremoriventer.

\section{Species profiles}

\section{Form 1. Niviventer fulvescens Gray, 1847}

Terra typica. Nepal, Katmandu.

Morphology. N. fulvescens is a rather small, graceful rat. The coloration of the dorsal side of the head and body are bright ruby reddish. The belly is white without any yellowish shade or any fulvous or brown spots. We could not obtain any individuals of this species in Northern Vietnam with fulvous spots on the belly. The tail is quite long (always longer than $140 \%$ of body length, on an average $148.5 \%$, and often longer than $150 \%$ ). In two of the seven individuals that we investigated, the tail was blackish ventrally on proximal one-third, sharply bicolor up to the end, except for the tip, which was completely brown, similarly to the last $1-2 \mathrm{~cm}$ of the dorsal side. The remaining individuals had tails with only a thin, progressively disappearing stripe and a lighter coloration of the ventral side that was hardly distinguishable by the naked eye and tail also have a look as brownish. The "chocolate-colored" tail itself could be described as "clambering", smooth, soft and flexible. Its tip was always intricately rolled into rings like a snake in fixed specimens. The dorsal side of the feet has a broad and obtuse deep-brown or chestnut stripe, which is also present on a metacarpus, but it is a little lighter there. The stripe is straight and almost reaches the fingers (Fig. $4 \mathrm{~A}$ ).

The skull is oblong and rather narrow in shape. The rostral part is distinctly gaunt and pointed, and the nasalia are narrow (Fig. 5). The zygomatic arches are slightly concave when viewed from above. The brain-
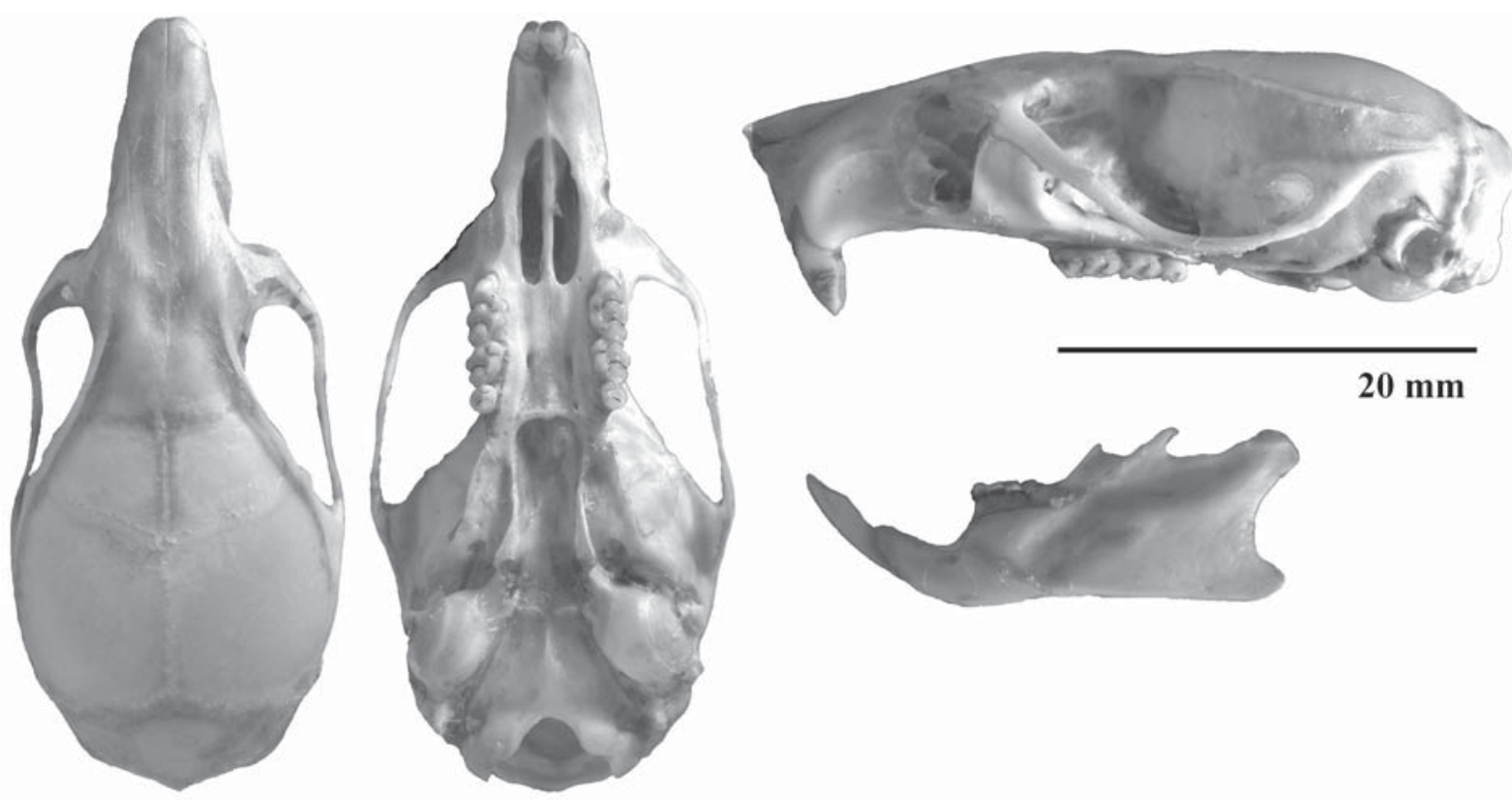

Figure 5. Skull of Niviventer fulvescens. Specimen ZMMU S-184809, Hoang Lien National Park, Lao Cai Province, Northern Vietnam. 

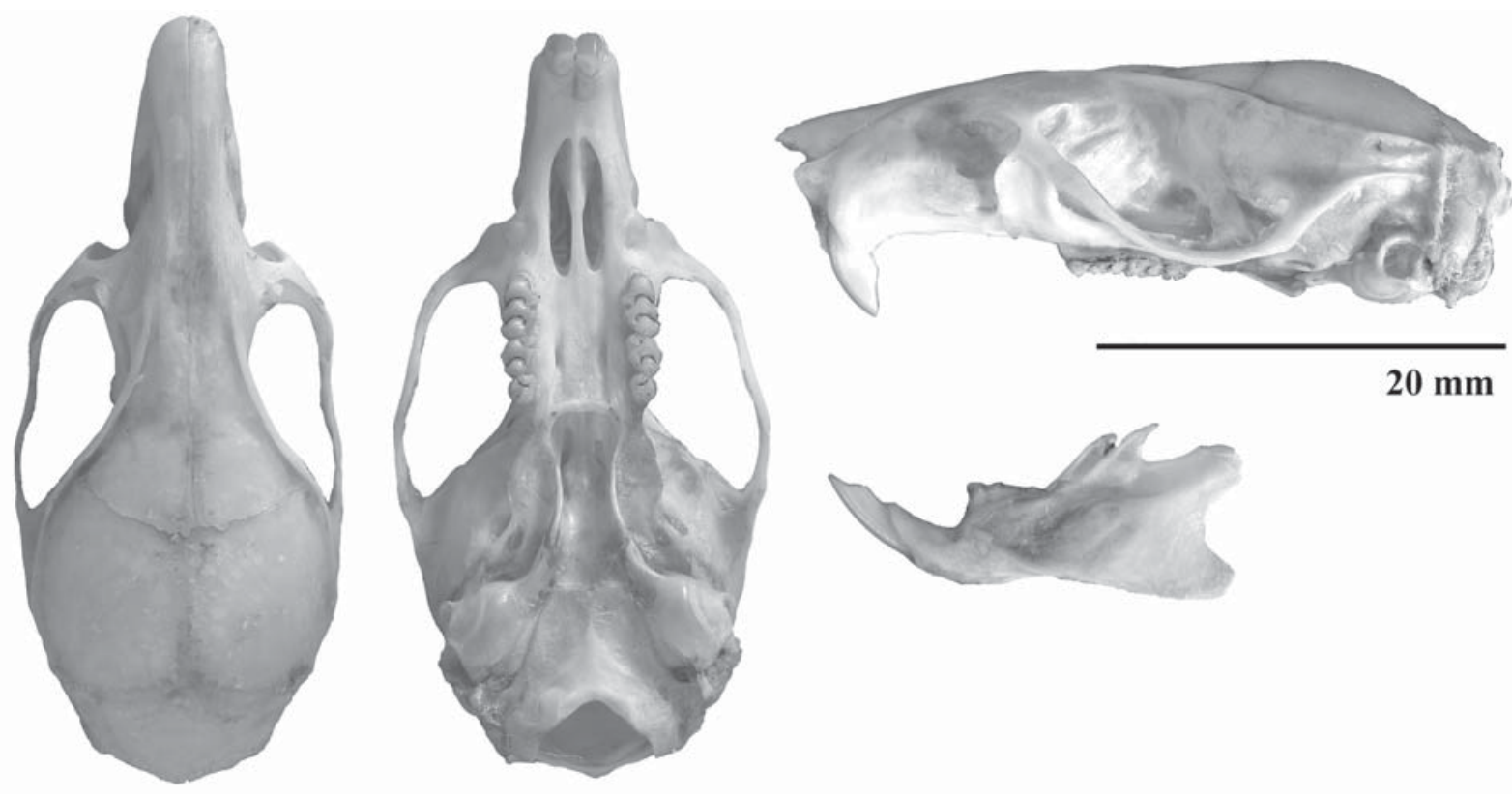

Figure 6. Skull of Niviventer huang. Specimen ZMMU S-186118, Bu Gia Map Nature Reserve, Binh Phuong Province, Southern Vietnam.

case is broad and rather low, the frontal line is straight when viewed from the side. The supraorbital ridges are undeveloped; its stretch along the dorsolateral side of the braincase as a narrow hem that does not reach to the occipital bone. The zygomatic plate is broad. Because of the elongated rostral part of the cranium, the incisive foramina are also long, extending no less than $0.4 \mathrm{~mm}$ beyond the line of the anterior limit of the first molars. The palatal bridge and mesopterygoid fossa are wide. The auditory bullae are small and angular in shape. The molars are rather large. The coronas are broad and covered by light colored enamel. The most unique traits of the skull in this species is the small size of the bullae (10-12\% less than in other species of Niviventer), which can be seen by the naked eye, and the incisive foramina, which are long and broad and stretch appreciably beyond the anterior molars. The above mentioned exterior and cranial characters are in full agreement with a detailed description of $N$. fulvescens given by Musser (1981). The most prominent trait based on general appearance and coloration is the dark-colored tip of the tail and the small-sized auditory bullae.

Distribution. According to the most of recent reviews, $N$. fulvescens is widely distributed in Southeastern Asia, including Indochina, the Malay Peninsula and the Sunda Isles (Molur et al., 2005; Musser et al., 2008). However, our genetic data indicated that only a few specimens originating from Lao Cai Province in Northern Vietnam (Hoang Lien National Park) can be ascribed to this species, along with other specimens that were identified in the Yunnan Province of China by Jing et al. (2007) and treated by these authors as $N$. cremoriventer. We not found any closely related specimens among the great number of sequences in the
BOLD database anywhere in the adjacent regions of Vietnam and China, which are predominantly a lowlands and plains. Nevertheless, a genetic form closely related to our $N$. fulvescens, but representing a highly reliable subcluster (so called N-2 species), was shown to distribute (Pagés et al., 2010) in mountainous regions close to Kanchanaburi (near Thailand-Burma border). Thus, it can be presumed that the species range may be restricted by highlands. Other, morphologically similar, but genetically distinct species inhabit the areas to the east and the south, from the Hoang Lien Mountains in lowlands of Indochina. The species is treated here as $N$. huang, and we suggest that this scientific name should be restored as a proper taxon.

\section{Form 2. Niviventer huang Bonhote, 1905}

Terra typica. China, Fujian Province, Kuatun.

Morphology. This is a moderately sized rat as large as a typical $N$. fulvescens or only a little larger. The general coloration of the upper side is brightly reddishbrown, but in contrast to $N$. fulvescens, fulvous yellowish, orange and rusty tints are dominant in the pelt coloration. The hind and a front legs show a light brown band. This light brown band on the dorsal side of the foot, which extends straight from the ankle almost up to the fingers, is appreciably lighter and thinner (to 1.5-2 $\mathrm{mm}$ ) (see Fig. 4 B) than in typical $N$. fulvescens (form 1 in our study) according to Musser (1981). The trait is in full agreement with the species characteristics (under exactly this name) presented by Osgood (1932). The pelage of the belly, as well as the ventral side of the front legs, is white without any yellowish shade or fulvous or brown spots The tail is a little longer than the body (119-127\% of body length, on an average $123 \%$ ), rigid, sharply bicolored to the end, and unlike the north- 
ern $N$. fulvescens, it has no dark tip. It should also be noted that a white tip is never observed.

The species can hardly be distinguished from $N$. fulvescens based on cranial characters; this is the reason why it is usually considered synonymous (see Corbet \& Hill, 1993 for details). The skull morphology of the species is shown in Figure 6. Similarly to N. fulvescens, the skull of $N$. huang is oblong and rather narrow in shape, the rostral part is distinctly gaunt and pointed, and the nasalia are narrow, but they are somewhat heavier-built than in the former species. The zygomatic arches are heavier and also slightly concave when viewed from above. The braincase is broad and rather low, the frontal line is straight when viewed from the side. The supraorbital ridges are more developed, and the stretch along the dorsolateral side of the braincase is a narrow hem that reaches the occipital bone. The zygomatic plate is broad. The incisive foramina are quite long; the always reach the anterior limit of the first molars but do not often reach more than $0.1 \mathrm{~mm}$ beyond the line. The palatal bridge and the mesopterygoid fossa are wide, the bullae particularly small and angular in shape. The molars are rather large; the coronas are broad and covered by light colored enamel. Similarly to $N$. fulvescens the most unique traits of the skull are the small auditory bullae (9-12\% less than in any other species) and the long and broad incisive foramina, which usually do not stretch beyond the limit of the anterior molars. This is the only and rather feeble visually appreciable character in the skull structure that can serve as a distinctive feature for species delimitation.

Distribution. This species is widely distributed in Southern and Central Vietnam (found in Nam Cat Tien National Park and Vinh Cuu Nature Reserve, Dong Nai Province; Binh Chau Nature Reserve, Ba Ria - Vung Tau Province; Phu Quoc Island, Kien Giang Province; Lo Go Xa Mat Nature Reserve, Tay Ninh Province; Bu Gia Map Nature Reserve, Binh Phuoc Province; Ngoc Linh National Park, Kon Tum Province). Moreover, the BOLD contains closely related sequences (within $99 \%$ nucleotide identity) of the COI gene from the Dak Lak Province of Southern Vietnam and the Lang Son Province of Northern Vietnam in addition to sequences from the Kaoh Kong Province of Cambodia. A genetic form that is almost identical to our samples of $N$. huang from Nam Cat Tien and Lo Go Xa Mat, designated as $\mathrm{N}-1$, was recorded in the lowlands of NE Thailand (Phrae and Loei), close to Thailand-Laos border (Pagés et al., 2010). The sequences are similar but not completely identical and are recorded in BOLD from the Guizhou and Guangxi provinces of China (Shiwandashan Nature Reserve, $21^{\circ} 51^{\prime} \mathrm{N}, 107^{\circ} 53^{\prime} \mathrm{E}$, elevation $550 \mathrm{~m}$ a.s.l., and Jing Xin Country Provincial Nature Reserve, $\left.23^{\circ} 07^{\prime} \mathrm{N}, 105^{\circ} 06^{\prime} \mathrm{E}\right)$. The specimens from Con Son Island (Con Dao Isles, Ba Ria - Vung Tau Province, Southern Vietnam) were demonstrated to be genetically close (based on COI gene sequences) to mainland populations of $N$. huang, but they differ slightly in coloration, having dull grayish dorsal side of the head and the main coloration of the body. This population may represent a unique insular subspecies, but additional morphological analyses based on a larger series of specimens is needed to clarify the taxonomic status of Niviventer from Con Son.

Comments. Based on the close correspondence of our morphological samples to the detailed morphological description of external and cranial characters presented by Stephen \& Rudolf (2007) and the original species description, we can conclude that form 2 should be attributed to $N$. huang proper. In the paper by Stephen \& Rudolf(2007), a large series of skulls and skins from Fukien was investigated and considered to be $N$. fulvescens. Fukien is the type area for $N$. huang (see Bonhote, 1906), and the morphological characteristics of this series exactly correspond to $N$. huang. Stephen \& Rudolf (2007) also discussed some of the specific differences in pelt texture and coloration as well as the frequency of the occurrence of pectoral spots between these species and some other populations that probably belong to the original $N$. fulvescens, including ones that originated from its terra typica (Niethammer \& Martens, 1975). N. huang is widely distributed in Indochina, where it vicariate its closest relative, $N$. fulvescens. $N$. huang is apparently distributed mainly in lowland areas, though in Southern Vietnam it can be frequent even in low-mountain regions (for instance in Bu Gia Map Nature Reserve, at an altitude near $500 \mathrm{~m}$ a.s.1.), whereas $N$. fulvescens is mainly restricted by mountain regions in the north of Vietnam and to the west of the country. These species most likely are strictly allopatric and have not been recorded together. In spite of the close morphological similarity, the genetic divergence between them $(\mathrm{d}=0.083 \pm 0.009)$ (Table 2$)$ is sufficient to treat $N$. huang as a full species.

Form 3. Niviventer niviventer Hodgson, 1836

Terra typica. Nepal, Katmandu.

Morphology. This is one of the smallest rats with a generally ruby-red coloration of the upper part, and occasionally with a rusty hue that is less bright than in the sympatric species, $N$. fulvescens. The belly is white without any subtle yellowish shade. Three of the eight individuals from Northern Vietnam had a well-distinguishable brown or yellowish-brown spots generally on the chest or neck. The dorsal side of the front and hind legs has a broad deep brown or chestnut stripe that extends in a straight line almost to the fingers (Fig. 4 C). Tail is bicolor and quite long, more than $133 \%$ of the body length (on an average $145 \%$, frequently reaching up to $160 \%$ ). The tip is completely discolored or bare, with only few tiny dark patches on the upper side. The tail is straight and rigid and never bends, even in ethanol-preserved specimens.

The skull is small and light without prominent bony ridges. It is elongated and rather narrow in shape, the rostral part of cranium is appreciably less gaunt and broader than in the two species mentioned above, and the nasalia are broad (Fig. 7). The auditory bullae are rounded and are much greater in size than in the two 

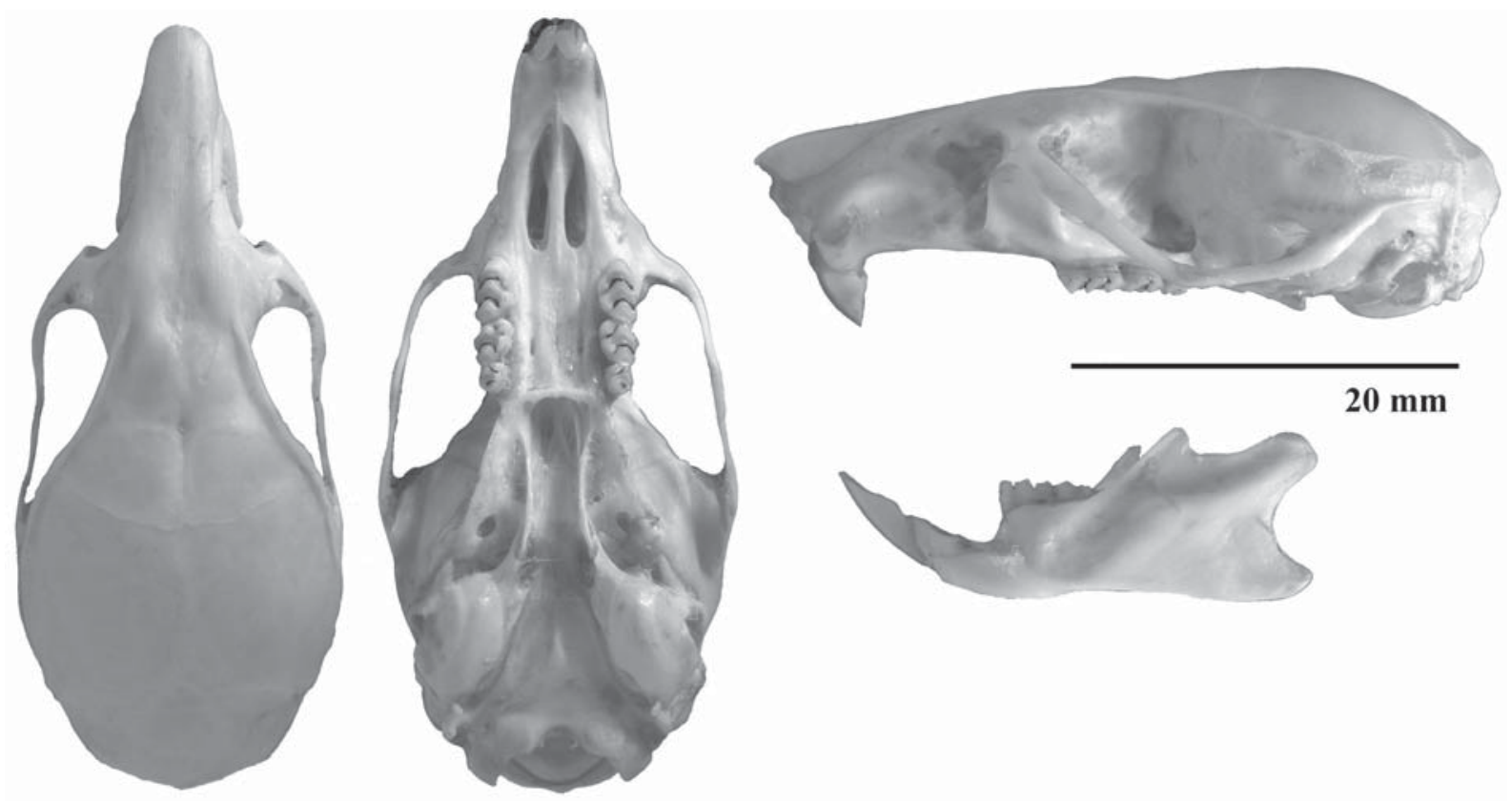

Figure 7. Skull of Niviventer niviventer. Specimen ZMMU S-184822, Hoang Lien National Park, Lao Cai Province, Northern Vietnam.

species described above. The zygomatic arches are somewhat concave when viewed from above, the braincase is generally rather low and broader, and the frontal line is straight. The supraorbital ridges are undeveloped; the stretch along the dorsolateral side of the braincase is a narrow hem that does not reach to the occipital bone. The zygomatic plate is narrow. The length of the incisive foramina is moderate; its posterior limits barely reach to the anterior limits of first molars. The palatal bridge is quite wide; the mesopterygoid fossa is rather narrow and elongated. The molars are lightly pigmented, rather coarse in shape, and have broad coronas. The most prominent diagnostic feature of the skull is the length of the incisive foramina, which barely reaches the molars row. Furthermore, the zygomatic plate is much narrower than in any other comparably sized species.

Distribution. We only captured this species in Hoang Lien National Park (Lao Cai Province, Northern Vietnam). Genetically identical samples were treated as $N$. fulvescens by Jing et al. (2007), the COI gene sequences are closely related (within $99 \%$ nucleotide identity) to those from Guangxi Province (Jing Xin Country Provincial Nature Reserve, $23^{\circ} 07^{\prime} \mathrm{N}, 105^{\circ} 06^{\prime}$ E), but samples misidentified as $N$. confucianus were also deposited into the BOLD database. Lunde et al. (2007) mentioned two morphologically distinctive morphs in the Huu Lien Nature Reserve (Northern Vietnam, Lang Son Province). Nevertheless, both morphs treated in the report as $N$. fulvescens. However, if the first of them exactly corresponds to $N$. fulvescens (our form 1), the other one is morphologically similar to our form 3, which we designated as $N$. niviventer. This finding allows us to assume that the species is widely distributed in southeastern China and the adjacent regions, but it has not yet been recorded south of Lang Son Province in Vietnam. Nevertheless, it may well be distributed to the west up to the Himalayan foothills.

Comments. We can assume that this species may be at least partly sympatrically distributed with the "original" $N$. fulvescens but not with $N$. huang. Based on morphological data, some authors (Corbet \& Hill, 1993; Musser \& Carleton, 2005) suggest that $N$. niviventer must be restricted in its distribution by Nepal. Unfortunately, this statement cannot be directly confirmed or refuted due to a lack of genetic samples from terra typica. The species designated here as form 3 is morphologically and genetically distinct from the sympatrically distributed $N$. fulvescens and $N$. confucianus. Based on some traits of general morphology and skull structure, it is most similar to $N$. niviventer, but not other Indochinese species of the genus. Thus, we propose that this species be considered $N$. niviventer until a comparative morphological-genetic investigation can be performed.

Form 4. Niviventer bukit Bonhote, 1903

Terra typica. Malaya, Bukit Besar, Jalor, elevation $760 \mathrm{~m}$ a.s.1.

Morphology. This is a very small rat that is approximately equal in size to $N$. niviventer but clearly smaller than $N$. confucianus and the sympatric $N$. tenaster. The overall color of the dorsal pelage is dull grayish brown and dark gravel. A fulvous tint is present, but it is not 

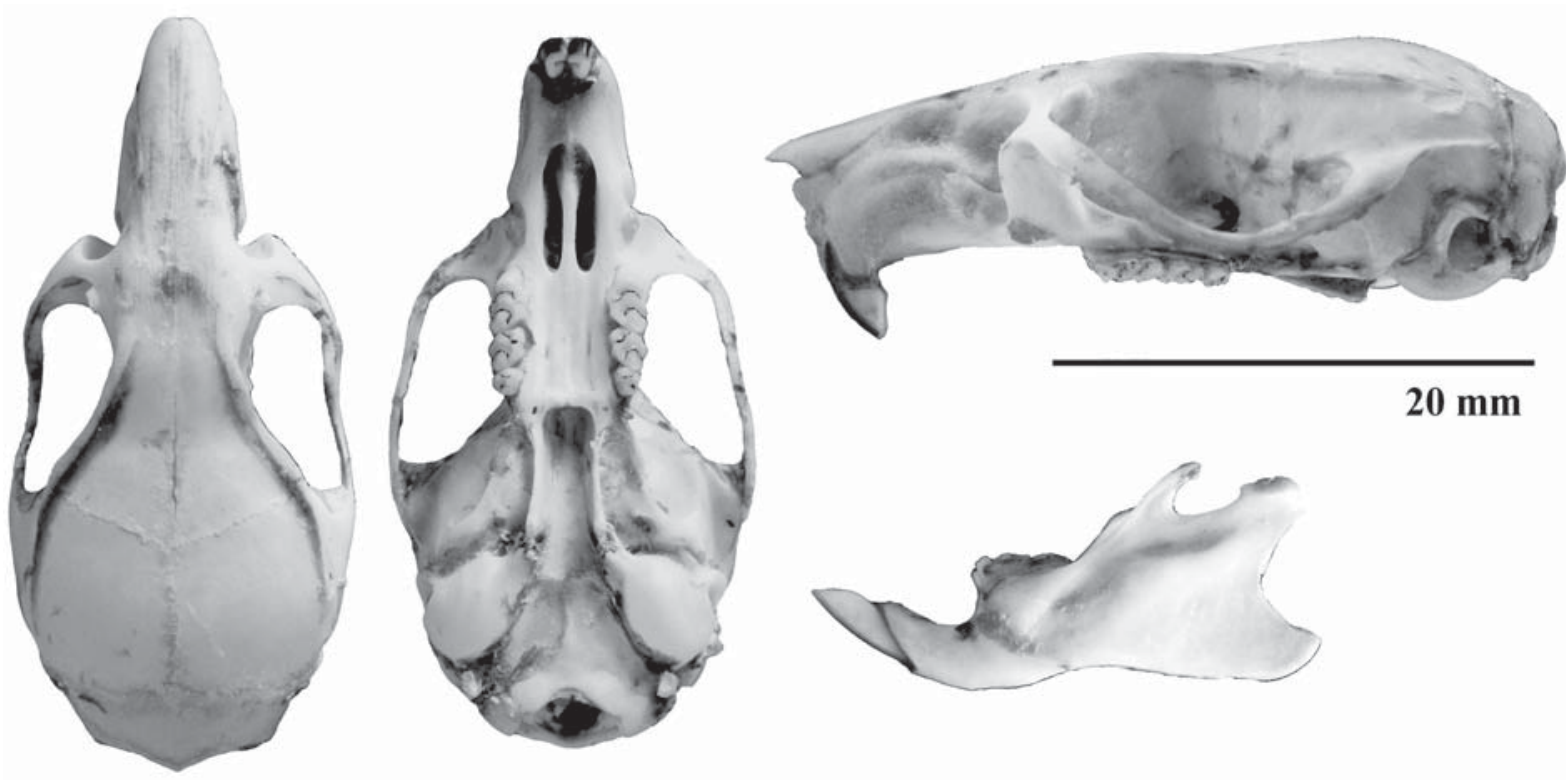

Figure 8. Skull of Niviventer bukit. Specimen ZMMU S-184800, Nam Cat Tien National Park, Dong Nai Province, Southern Vietnam.

bright. The dull grayish brown tints are the most appreciable in rear part of the back and rump. The belly is creamy or even obviously yellowish, providing a natural, evident distinctive feature of this species that is not the result of skin conservation. This yellowish hue is always apparent on carcasses or collected skins. In total, $62.5 \%$ of specimens from Bi Dup - Nui Ba and $20 \%$ of specimens from Nam Cat Tien have easily distinguishable brown or yellowish brown spots on the chest or neck. The lightly-colored area has an obvious constriction on the chest and neck to a rather narrow strip, providing a distinctive feature of this species that is lacking in $N$. tenaster and all other sympatric species. The dorsal surface of the hind feet is uniformly pale (Fig. $4 \mathrm{D}$ ), the grayish coloration of the upper side reaches the calcaneal area. The tail is fuzzy and bicolored, and it is a little longer than the body (110-122\% of body length, on an average $119 \%$ ) with thin, short, creamy to whitish hairs that are more dense towards the tip. The tail is light to medium brown on the dorsal side and pale on the ventral side. The tail tip coloration is similar to $N$. niviventer and $N$. tenaster, and in about a half of the individuals, the dark coloration of the upper side diminishes toward the end. Nevertheless, a completely discolored tip is never present.

The skull is compact but looks a massive (Fig. 8), elongated and rather narrow. The rostral part of the cranium is oblong and gaunt. The nasalia are broad in the proximal part and sharply narrowed toward the frontal bones. The skull is appreciably narrowed in the interorbital area, the zygomatic arches are parallel to the braincase sides when viewed from above. The braincase is generally rather low and broad. The frontal and rostral lines form a visually distinctive obtuse angle when viewed from the side. The supraorbital ridges are well developed, especially in the frontal part; the stretch along the dorsolateral side of the braincase is a wide shelf and reaches to occipital bone. The zygomatic plate is quite broad. The incisive foramina are narrow and moderately long; the posterior limits hardly if at all reach the anterior limits of the first molars. The palatal bridge and the mesopterygoid fossa are wide. The auditory bullae are rounded and appreciably inflated. The molars are comparatively minute, rather narrow in shape and lightly pigmented. The most prominent diagnostic feature of skull morphology is a comparative length of incisive foramina that barely reaches the molars row. Additionally, the zygomatic plate is much narrower than in any other comparably sized species.

Distribution. We captured this species in the Dong Nai and Lam Dong provinces of Southern Vietnam (Nam Cat Tien and Bi Dup - Nui Ba National Parks, and Vinh Cuu Nature Reserve). Identical COI sequences are also reported in BOLD from Central Laos.

Comments. This form is usually treated as closest and morphologically similar to N. fulvescens. Formerly $N$. bukit was treated as a distinct species (Corbet \& Hill, 1993), but at present, it is listed as a synonym of $N$. fulvescens (Musser \& Carleton, 2005). However, as it can be seen both from its phylogenetic position (Fig. 3) and from the genetic distances (interspecies d's $=0.069$ 0.153; Table 2, see Balakirev \& Rozhnov, 2010 for details), this relationship is obviously artificial. 

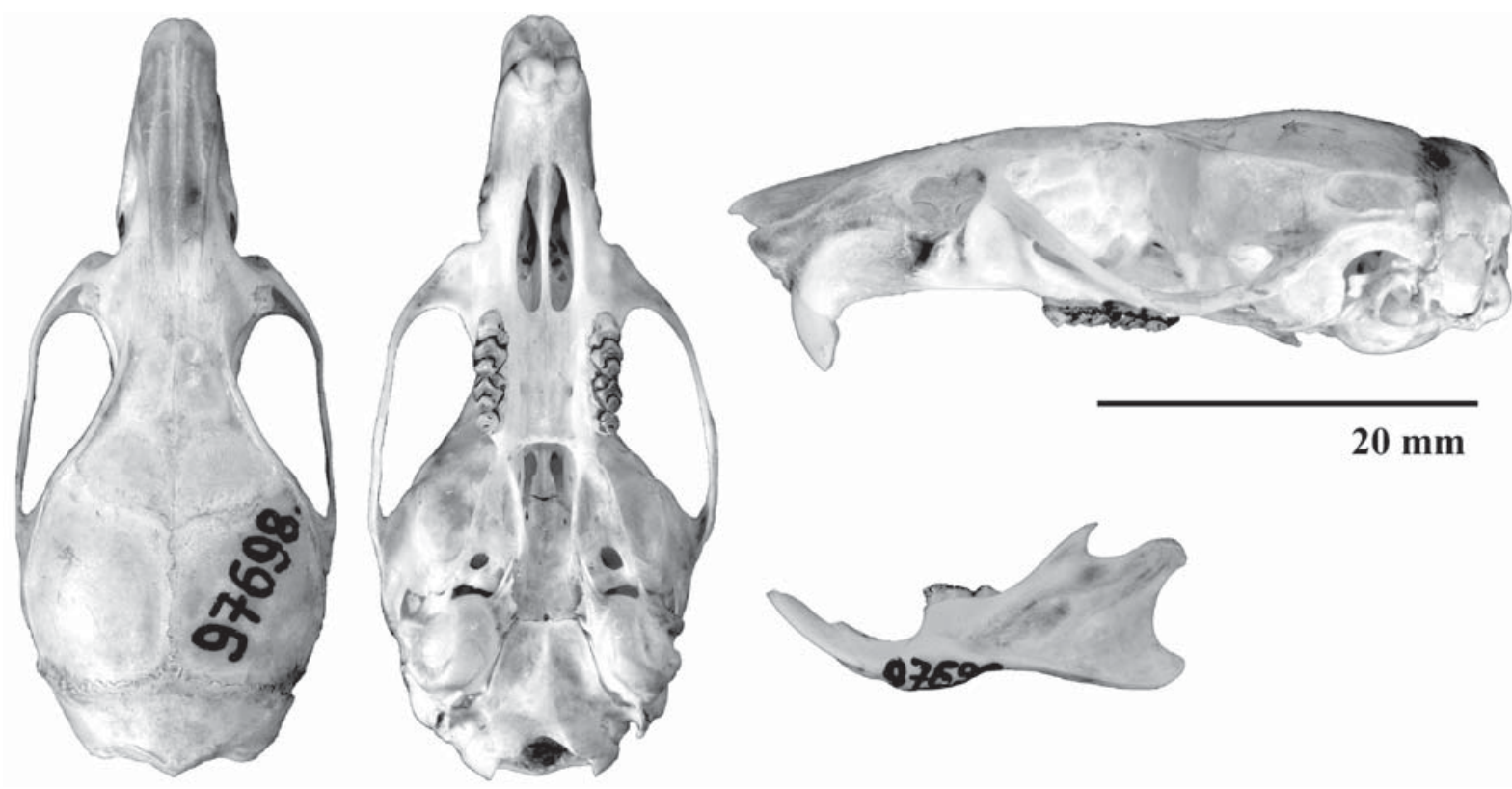

Figure 9. Skull of Niviventer confucianus. Specimen ZIN 97698, Hoang Lien National Park, Lao Cai Province, Northern Vietnam. 1871

Form 5. Niviventer confucianus Milne-Edwards,

Terra typica. China, Szechwan, Moupin.

Morphology. This is a large rat. The overall color of the dorsal pelage is tinged dark (chocolate) brown to reddish cinnamon brown, and it is slightly shiny. The hairs are gray at the base and then turn to dark brown or light reddish-brown. The fur is darkest along the middle of the back, and it gradually turns lighter and more reddish-cinnamon towards the sides. In most specimens, the fur is relatively smooth and shows a clear direction of the hair. There are a few longer, more sturdy but flexible guard hairs. The pelage of the belly, as well as the ventral side of the front legs, is creamy whitish or creamy-yellowish. It is well separated from the dorsal color by a clear line. Generally, the belly is uniform in color, sometimes being more yellowish in the area between the hind or front legs. In one of two specimens, a small fulvous spot on the breast was present as a tiny light brown patch. Usually, the hind feet show a brown band of varying thickness between the lower hip area and the ankle on the ventral side (Fig. 4 E). The tail is bicolor, longer than the body $(125-135 \%$ of body length, on an average 130\%), and covered with thin, short, creamy to whitish hairs that are more dense towards the tip. The tail is light to medium brown on the dorsal side and creamy to very lightly brown on the ventral side. Only the most proximal part on the ventral side may be of the dark dorsal color. The dorsal brown color fades towards the tail tip to form a white tip.

The skull is large, elongated and rather narrow in shape. The rostral part of the cranium is not gaunt, and the nasalia are broad (Fig. 9). The zygomatic arches are almost parallel to the sides of the braincase when viewed

from above. The braincase, and especially the interorbital area, is low, and the frontal line is almost straight when viewed from the side. The supraorbital ridges are undeveloped; they stretch along the dorsolateral side of the braincase as a narrow hem, but nevertheless, they reach the occipital bone. The zygomatic plate is broad. The incisive foramina are long and narrow, and they are sharpened at the rostral end; their posterior limits hardly if at all reach the anterior limits of the first molars. The palatal bridge is short and wide; the mesopterygoid fossa is narrow. The auditory bullae are moderate in size, rounded, and slightly inflated. The molars are well pigmented, rather small in size in comparison with the general size of skull, and the coronas are narrow.

This species can be most simply separated from $N$. niviventer and $N$. bukit based on general size; it is much larger than the latter two. In comparison with $N$. tenaster, this species has a similar size. The length of the incisive foramina of $N$. confucianus is always greater than the length of the palatal bridge, and the posterior ends of the foramina always reach the molar row limit, and the zygomatic plate is broad. $N$. tenaster, on the contrary, has incisive foramina that is shorter than the length of the palatal bridge, it sometimes does not reach the molar row limit, and the zygomatic plate is appreciably narrower.

Distribution. In Vietnam, this species can only be found in mountains of Hoang Lien National Park (Lao Cai Province, Northern Vietnam) as well as in the mountains of Yunnan, China as described by Jing et al. (2007). We did not find any closely related samples among the sequences in the BOLD database from any of the adjacent regions (Chinese provinces Guizhou and Hunan). All of the reference sequences here are not 

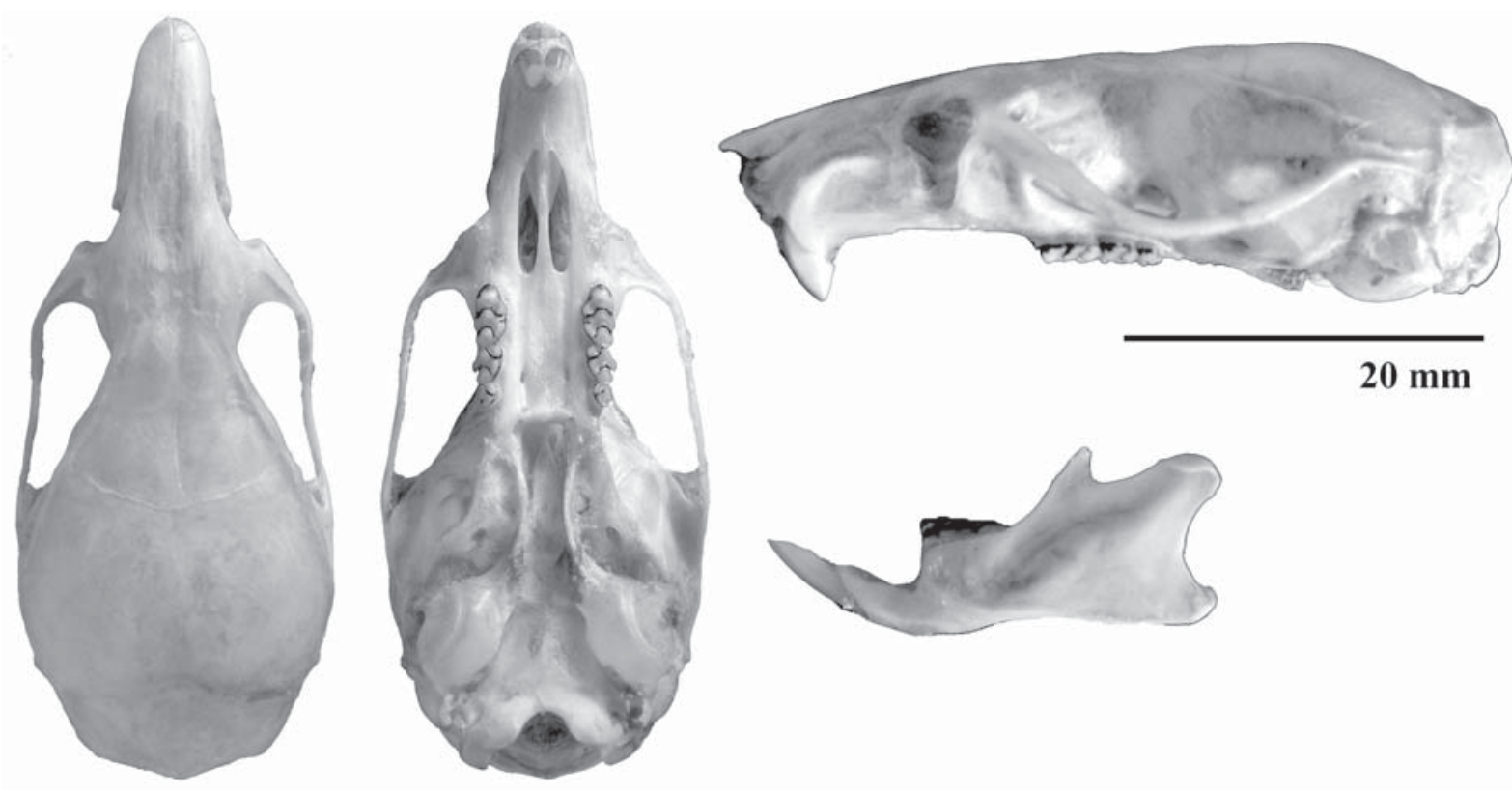

Figure 10. Skull of Niviventer tenaster. Specimen ZMMU S-184827, Bi Dup - Nui Ba National Park, Lam Dong Province, Southern Vietnam.

related closely enough (less than $98 \%$ COI nucleotide identity) to be obviously regarded as the same species, in spite of being called by the same name $N$. confucianus. The last finding allows us to surmise that this species is distributed in a large area in China, but this presumption remains to be evaluated through a detailed and widespread investigation (Balakirev et al., in press).

Comments. A detailed description of this species was made by Stephen \& Rudolf (2007). Our specimens from Hoang Lien National Park are consistent with this description.

Form 6. Niviventer tenaster Thomas, 1916

Terra typica. Southern Burma, Kayin State, Mulayit (also spelled Mooleyit, Mulaiyit, Muleyit) Taung (= peak), $16^{\circ} 11^{\prime} \mathrm{N}, 98^{\circ} 32^{\prime} \mathrm{E}$, elevation $1525-1830 \mathrm{~m}$ a.s.1.

Morphology. This is a large brownish rat that is much larger than any other species except for $N$. confucianus, which is nearly equal in size. The bright rubyred coloration of the upper part is much less prominent in comparison with $N$. fulvescens. The overall color of the dorsal pelage is dark brown but without the prominent chocolate-brown hue that is a characteristic feature of $N$. confucianus. This species generally appeared similar in coloration to $N$. bukit, but it appears larger and has more sturdy but flexible guard hairs. The belly is white without any fulvous or brown spots. The hind feet bear a broad brown or chestnut stripe (Fig. 4 F), which extends straight almost to the fingers and disappears 3-4 $\mathrm{mm}$ before them. The tail is particularly long (always longer $148 \%$, on an average 151\%), sharply bicolored, and it may retain the permanent dark coloration of the upper side up to the end; however, in about half of the individuals, the dark coloration became a faltering. Nevertheless, a completely discolored tail tip, which is characteristic of $N$. niviventer, is never present.

The skull morphology of the species is shown in Figure 10. This is the only species with a greatest skull length that exceeds $41 \mathrm{~mm}$ (see Corbet \& Hill, 1993), and it could be up to $42 \mathrm{~mm}$ in our samples. At the same time, the skull is lightly built and not coarse. It is quite elongated and rather narrow in shape. The rostral part of the cranium is oblong and seems to be gaunt; nevertheless, the nasalia are broad and rather short. The skull is appreciably narrowed in interorbital area. The zygomatic arches are slightly concave when viewed from above. The frontal line is slightly convex when viewed from the side. The supraorbital ridges are undeveloped; they stretch along the dorsolateral side of the braincase as a narrow hem and do not reach to occipital bone. The zygomatic plate is narrow. The incisive foramina are rather short and narrow, and their posterior limits usually do not reach the fore limits of the first molars. The incisive foramina are always shorter than the length of the palatal bridge. The palatal bridge is wide, and the mesopterygoid fossa is narrow and oblong. The auditory bullae are large, rounded, and inflated. The molars are considerably larger than in $N$. confucianus, and the coronas are broad and covered by dark enamel.

Distribution. This species was only found in the highlands of the Dalat Plateau (Bi Dup - Nui Ba National Park, Lam Dong Province, Southern Vietnam) within the same elevation zone as $N$. confucianus. Mitochondrial DNA sequences related to this species are currently not present in the BOLD database, so it is difficult to make assumptions about its distribution range. 

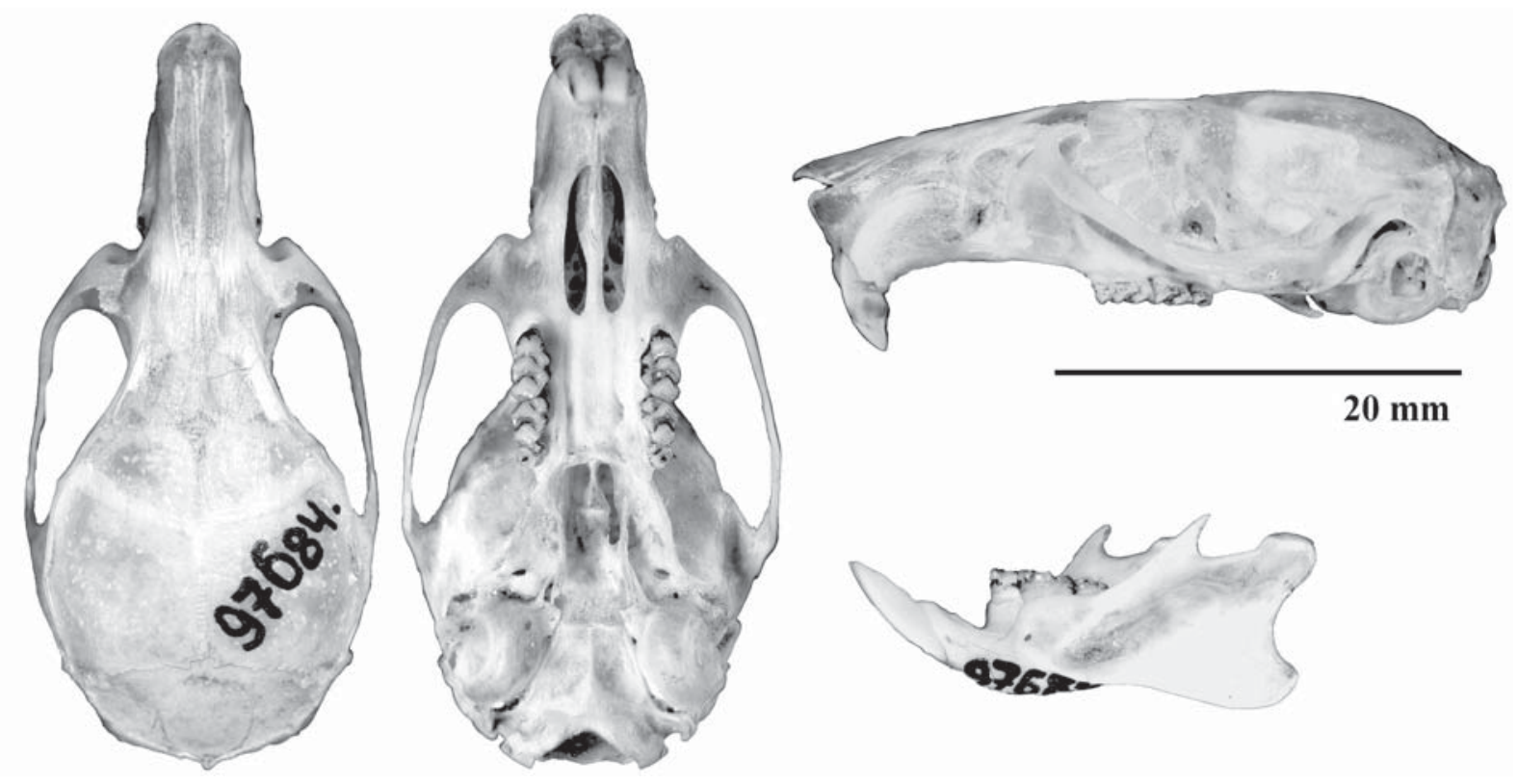

Figure 11. Skull of Niviventer langbianis. Specimen ZIN 97684, Bi Dup - Nui Ba National Park, Lam Dong Province, Southern Vietnam.

\section{2}

Terra typica. Southern Vietnam, Lam Dong Province, Langbian Mountains, Langbian Peak, elevation 1800-2300 m a.s.l.

Morphology. This rat is generally moderately sized. The coloration of the upper side is brownish-gray, the fur is particularly dense, smooth and downy without any spines or guard hairs. The overall color of the dorsal pelage is generally dull grayish with a touch of fulvous color. The pelage of the belly, as well as the ventral side of the front legs, is white without any yellowish shade. Occasionally, fulvous or brown spots can be observed. The ventral side coloration is separated from the dorsal color by a clear line. The tail is long and slender, and it is much longer than the body (135$155 \%$ of body length, on an average $140 \%$ ). It is uniformly tinged dark (chocolate) brown from the proximal part to the end. It is well covered with hair, but it lacks a terminal brush. The ears are relatively short, and the vibrissae are particularly long, extending backward well beyond the head. The dorsal sides of fore and hind feet have a broad brown or chestnut stripe that extends straight beyond to the middle part of the foot. The stripe becomes progressively narrower and disappears near the fingers so that the most distal third of the foot and the fingers are completely white (Fig. 4 G).

The skull appears rather massive, but it is compact, broad, rounded in shape, and bony ridges are not prominent (Fig. 11). The rostral part is appreciably longer in comparison with the closest relative, $N$. cremoriventer, but at the same time, it is shorter than in aforementioned species of similar size, such as $N$. fulvescens, $N$. huang, $N$. niviventer and $N$. bukit. The nasalia are elongated but not gaunt at the tip. The skull is quite broad in the interorbital area, the zygomatic arches are wide and convex when viewed from above, the braincase is high and broad, and the frontal line is obviously convex when viewed from the side. The supraorbital ridges are poorly developed, and they are barely visible along the dorsolateral limit of the braincase and do not reach the occipital bone. The zygomatic plate is broad. The incisive foramina are moderately long, quite broad, and the hardly, if at all, reach the line of first molars. The palatal bridge and the mesopterygoid fossa are quite wide, and the latter are very short. The auditory bullae are rather large, rounded and smooth. The molars are considerably large with broad coronas, and they are covered by dark enamel.

Distribution. We found this species in the highlands of the Dalat Plateau (Bi Dup - Nui Ba National Park, Lam Dong Province, Southern Vietnam), approximately of $70 \mathrm{~km}$ from the type locality (Langbian Mountain), at the same elevation. COI sequences that are closely related to our samples (up to $99 \%$ nucleotide identity) obtained from animals caught in Central Laos and Northern Vietnam (Lang Son Province, Lang Dat District, $4 \mathrm{~km}$ to the west of Huu Lien National Park on elevation $500 \mathrm{~m}, 21^{\circ} 68^{\prime} 30^{\prime \prime} \mathrm{N}, 106^{\circ} 33^{\prime} 03^{\prime \prime} \mathrm{E}$ ) are deposited in BOLD. A genetic line that is closely related to our $N$. langbianis samples but that represents a special subcluster (so called N-4 species) was discovered by Pagés et al. (2010) in Khammouane Province, Central Laos. The authors failed to make a clear decision about the taxonomic attribution of the sample either it belongs to N. langbianis or Chiromyscus chiropus. Here, we can argue that it belongs to the former species, and we provide strong genetic evidence in 

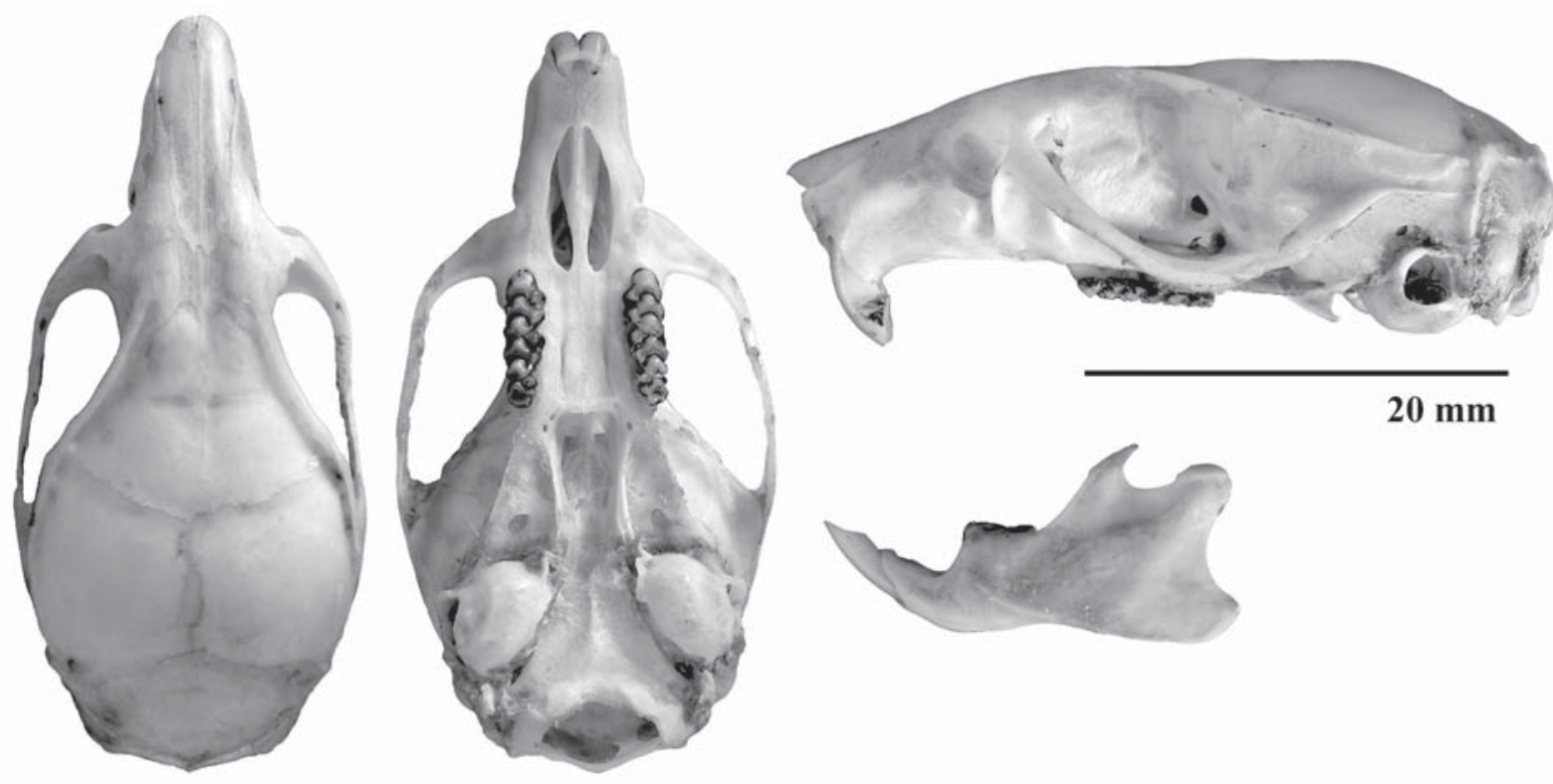

Figure 12. Skull of Niviventer cremoriventer. Specimen ZMMU, S-186116, Vinh Cuu Nature Reserve (= Ma Da Forest), Dong Nai Province, Southern Vietnam.

support of a wide distribution of $N$. langbianis in Central and Northern Indochina.

Comments. It should be noted that the species we refer to here as $N$. langbianis does not completely correspond to the species description presented by G. Musser (Musser, 1973, 1981; Musser \& Carleton, 2005). Our animals lack some of the external characteristics, such as an olive hue in the coloration of the upper side or a creamy colored belly. Likewise, according to Musser's data, the incisive foramina in $N$. langbianis extend to the level of the first molars, but they do not exceed this limit in our samples from the Dalat Plateau (Fig. 12). It may be that the geographical variability of this species is still being underestimated.

Form 8. Niviventer cremoriventer Miller, 1900

Terra typica. Southern Peninsular Thailand, Trang Province, Trang, $07^{\circ} 30^{\prime} \mathrm{N}, 99^{\circ} 18^{\prime} \mathrm{E}$.

Morphology. This is a small and brightly colored rat. The coloration of the upper side is bright fulvous with a pronounced orange hue, which is most prominent in the humeral area. The fur is dense, smooth and downy with some blackish flexible guard hairs along a middle line of the back. A prominent buff-orange area separates the dorsal side coloration from the creamyyellowish belly. The sides are more brightly colored than back. The cheek, lateral surface of the neck and the front legs are bright yellowish-orange, and this hue is contrasted with the more dull coloration of the other parts of the body. The dorsal sides of both front and hind feet and even the proximal phalanx are completely buffy-orange (Fig. $4 \mathrm{H}$ ). The finger pads both in the front and hind feet are appreciably more developed than in N. langbianis. The claws are large, the thumbs of the hind feet bear a plain nail-like claw. The tail is long and slender, and it is much longer than the body (128-148\% of body length, on an average $138 \%)$. It is uniformly tinged dark brown from the proximal part to the end. It is quite thick and covered with hair. The ears are large and dark colored, the black vibrissae are long and turned backward well beyond the ears.

The skull is broad and rounded in shape. The rostral part is broad and blunt, and the nasalia are rather wide and elongated (Fig. 12). The interorbital area is appreciably flattened, the braincase is rather low and wide; the front line is obviously convex when viewed from the side. The supraorbital ridges are well developed, stretching to the dorsolateral limit of the braincase. The zygomatic plate is rather narrow. Because of shortened rostral part, the incisive foramina are rather short and broad, but they reach to the first molar line. The palatal bridge and mesopterygoid fossa are wide. The auditory bullae are small and rounded. The molars are considerably large with broad coronas, and they are covered by a dark brownish to black enamel.

Distribution. We collected two adult specimens in the Vinh Cuu Nature Reserve (= Ma Da Forest) at the border of the Dong Nai and Binh Phuoc provinces in Southern Vietnam, one specimen in the Binh Chau Nature Reserve, Ba Ria - Vung Tau Province and one specimen in the outskirts of the Lo Go Xa Mat Nature Reserve, Tay Ninh Province, also in Southern Vietnam.

Comments. $N$. cremoriventer is almost always misidentified and attributed to $N$. langbianis in Vietnam because this species was not known to inhabit the areas to the north from the Isthmus of Kra (Musser, 1973, 1981; Corbet \& Hill, 1993; Musser \& Carleton, 1993, 2005), and documented samples originating from anywhere in Indochina are lacking. Therefore, this species 
was not listed in the most of recent reviews (Corbet \& Hill, 1993; Musser \& Carleton, 1993, 2005; Francis, 2008; Smith \& Lunde, 2008). It is not clear what species is being recorded under that name by some Vietnamese (Dang Huy Huynh et al., 1994) and Chinese authors (Zhang et al., 1997) who have listed this species for Northern Vietnam and China. The specimens from Yunnan in China regarded as a $N$. cremoriventer by Jing et al. (2007) were found to be typical $N$. fulvescens (see above). This confusion was apparently caused by the fact that more than one third of individuals of $N$. fulvescens have a distinct brownish coloration of the ventral part of the proximal one third of the tail.

Two adult females from the Vinh Cuu Nature Reserve (= Ma Da Forest) and the Binh Chau Nature Reserve were genotyped by both cyt $b$ and COI genes in this study. These sequences resulted in a separate cluster in the tree attributed to $N$. cremoriventer. Based on external characters and skull morphology, as well as their genetic divergence, this species (form 8) is clearly distinct from $N$. langbianis and bears specific characters that are in full agreement with the characteristics of $N$. cremoriventer presented by Musser (1973) for Malayan samples. We therefore suggest that $N$. cremoriventer does exist in the fauna of Southern Vietnam.

\section{Identification of Niviventer species}

Based on visual examination of the skull morphology of genotyped animals, we can conclude that Niviventer species can generally be separated without complex statistical analysis. The Niviventer species have a number of characteristics in the exterior and skull morphology (Figs. 5-12, APPENDIX III) that are appropriate for species identification. These are the traditionally used characters (Musser, 1973, 1981; Musser \& Newcomb, 1983; Corbet \& Hill, 1993; Stephen \& Rudolf, 2007), such as coloration of the head and body, the pattern of coloration of the dorsal side of the metatarsus (feet) (Fig. 4), coloration of the tail, and especially the tip of tail, the size of the auditory bullae, and the comparative length of the incisive foramina. Furthermore, other measurements are useful for species diagnostics - comparative breadth of interorbital area (IIB), comparative length and breadth of rostrum (ILB and IBR1), incisive foramina and palatal length ratio (ILBP1), and comparative size of zygomatic plate (IBZP). The diagnostic characters are summarized in Table 3.

Niviventer fulvescens and $N$. huang can be easily distinguished from each other by the size of the bulla and the length of the incisive foramina. The incisive foramina extend to $0.4 \mathrm{~mm}$ beyond the level of the first molars in $N$. fulvescens and only reach the line of the first molars in $N$. huang. It can also be useful to observe the supraorbital ridges, which reach to the occipital bone in $N$. huang but not to the limit of occipital bone in $N$. fulvescens. The most straightforward way to distinguish these species is based on the body coloration. The
$N$. fulvescens has a distinctly reddish coloration, whereas $N$. huang usually has yellowish or orange tones in the dorsal side coloration rather than reddish tones. Moreover, the strip on hind feet is considerably lighter and narrower in the latter species.

$N$. langbianis and $N$. cremoriventer can be most easily separated from all other species by their unicolored dark tail, the broad zygomatic plate, the short rostral part and the widespread zygomatic arches. The characters that can distinguish between these two species are the length of the nasalia and length of rostrum; both these measurements are much lesser in $\mathrm{N}$. cremoriventer. The variability of the character that has been traditionally used (Musser, 1973) is the length of the incisive foramina, and this should be carefully tested for this pair of species.

The other four phylogenetically closely related species all have large bullae and can be separated by body size into two pairs. The lesser ones ( $N$. niviventer è $N$. bukit) can be distinguished one from another by the body coloration and length of tail. $N$. niviventer is distinctively reddish (Table 3 ) and has a much longer tail. Lacking the skin, the most prominent diagnostic traits are the length of the incisive foramina, which always reach well beyond the fore limits of the first molars in N. bukit, but only reach the line in N. niviventer. Moreover, the later species has an appreciably narrower zygomatic plate. The pair of large-sized species, $N$. confucianus and $N$. tenaster, is rather similar in general appearance. The only diagnostic character in external morphology is the presence of an appreciably fulvous, buffy hue in $N$. confucianus. However, these species can be easily separated based on skull morphology; ILBP is always $<1$ and the incisive foramina always reach the fore limit of the first molars in $N$. confucianus, whereas ILBP always $>1$ and the incisive foramina often do not extend to the limit of the first molars in N. tenaster (Table 3).

\section{Conclusions}

In summary, we have concluded that the taxonomy of the genus Niviventer that was established 20-30 years ago (Musser, 1973, 1981; Corbet \& Hill, 1992; Musser \& Carleton, 1993), with the exception of minor modifications to the attribution of some morphs and species, is consistent with the actual biodiversity. Unfortunately, more recent taxonomies are not equally consistent (Lunde \& Nguyen Truong Son, 2001; Musser \& Carleton, 2005; Francis, 2008; Smith \& Lunde, 2008) and therefore are not supported.

Based on the aforementioned data, we disagree with the almost generally accepted thesis that many of the Niviventer species are difficult to identify on the basis of morphological traits. The problem arises from the original misidentification of species resulted from the incorrect taxonomy. Misidentification and combined multispecies sampling give rise to biased statistical data. Inaccurate measurements among the original set 
Taxonomic revision of Niviventer from Vietnam: a morphological and molecular approach

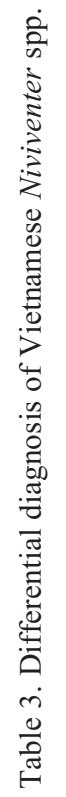

\begin{tabular}{|c|c|c|c|c|c|c|c|c|c|c|c|c|c|c|}
\hline \multirow{2}{*}{ 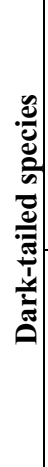 } & 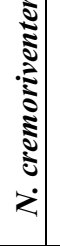 & $\begin{array}{l}\stackrel{0}{\underline{z}} \\
\stackrel{0}{g}\end{array}$ & $\begin{array}{l}\stackrel{\infty}{ \pm} \\
\stackrel{\Xi}{J} \\
\end{array}$ & 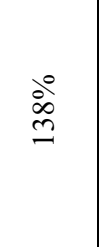 & 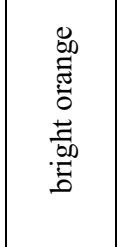 & 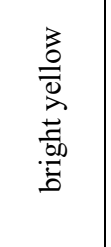 & 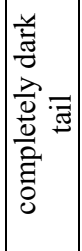 & 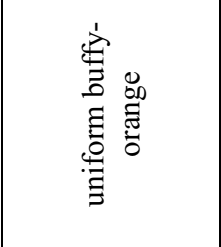 & $\begin{array}{l}\frac{t}{0} \\
\frac{0}{n}\end{array}$ & 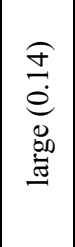 & 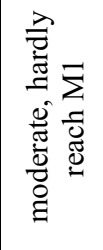 & 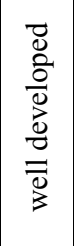 & & \\
\hline & 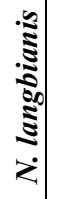 & $\begin{array}{l}\frac{0}{\vec{z}} \\
\stackrel{\vec{g}}{g}\end{array}$ & $\left|\begin{array}{l}n \\
n \\
n \\
n \\
n\end{array}\right|$ & 高 & 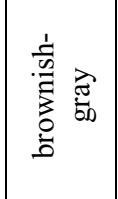 & 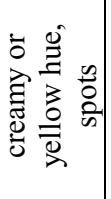 & 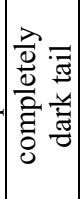 & 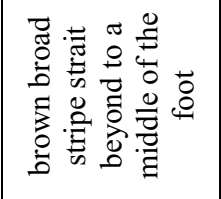 & $\begin{array}{l}\frac{t}{0} \\
\frac{d}{n}\end{array}$ & 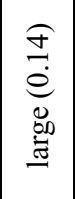 & 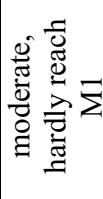 & $\left|\begin{array}{ll}2 & 0 \\
\vdots & 0 \\
0 & 0 \\
0 & 0 \\
0 & 0 \\
0 & 0 \\
0 & 0\end{array}\right|$ & $\begin{array}{l}\tilde{Z} \\
\tilde{0} \\
0 \\
0\end{array}$ & \\
\hline \multirow{2}{*}{ 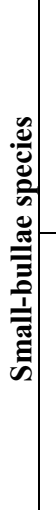 } & $\begin{array}{l}0 \\
\mathbf{5} \\
\mathbf{z} \\
\dot{z}\end{array}$ & $\begin{array}{l}\stackrel{0}{\bar{g}} \\
\stackrel{0}{g}\end{array}$ & $\begin{array}{l}\hat{\jmath} \\
\mathfrak{a} \\
\stackrel{\Xi}{\Xi}\end{array}$ & ळें & 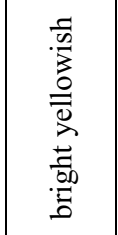 & 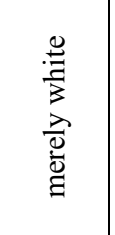 & 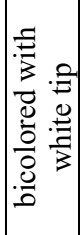 & 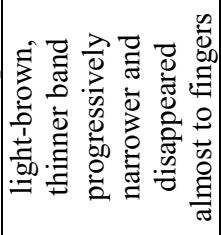 & 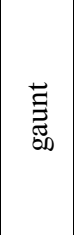 & 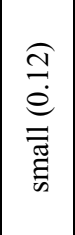 & 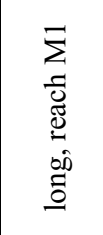 & 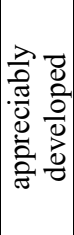 & 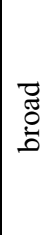 & \\
\hline & 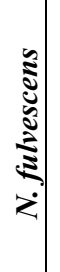 & $\frac{\varrho}{\frac{0}{\Xi}}$ & $\begin{array}{l}0 \\
0 \\
n \\
1 \\
+ \\
d\end{array}$ & $\begin{array}{l}\stackrel{\circ}{ } \\
\text { o } \\
\text { o }\end{array}$ & 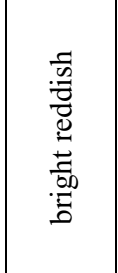 & 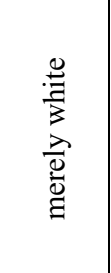 & 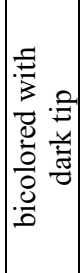 & 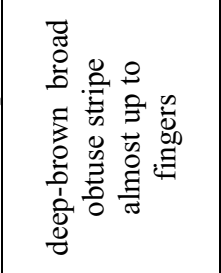 & 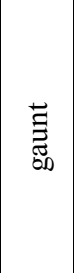 & 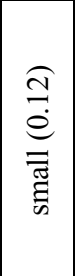 & 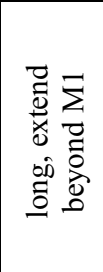 & 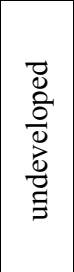 & $\begin{array}{l}\tilde{J} \\
0 \\
0 \\
0\end{array}$ & \\
\hline \multirow{5}{*}{ 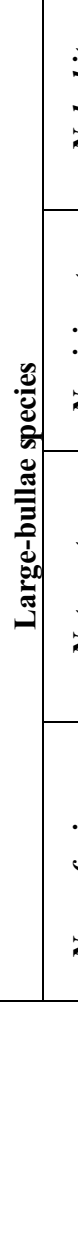 } & $\begin{array}{c}\vdots \\
\vdots \\
\vdots \\
z \\
z\end{array}$ & $\begin{array}{l}\overline{\bar{\varpi}} \\
\text { 施 }\end{array}$ & $\begin{array}{l}\text { İ } \\
\mathfrak{J} \\
ٍ \\
=\end{array}$ & $\stackrel{\circ}{ٍ}$ & 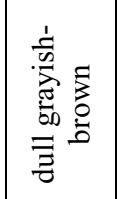 & 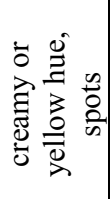 & 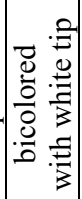 & 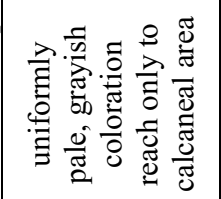 & 農 & 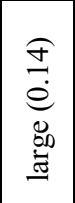 & 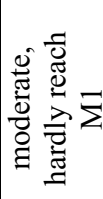 & 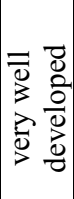 & \begin{tabular}{|l}
0 \\
0 \\
0 \\
0 \\
0 \\
0 \\
0 \\
0
\end{tabular} & \\
\hline & 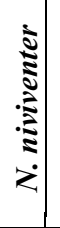 & 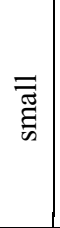 & $\begin{array}{c}8 \\
0 \\
1 \\
m \\
-\end{array}$ & ì & 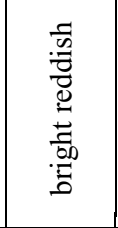 & 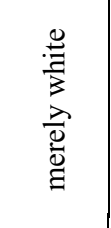 & 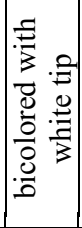 & 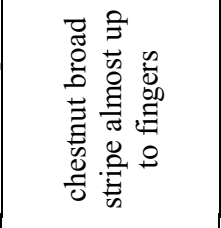 & 䓌 & 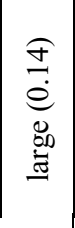 & 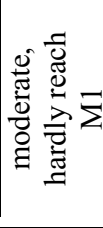 & 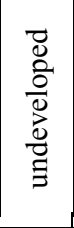 & 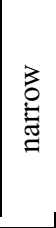 & \\
\hline & 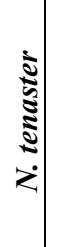 & 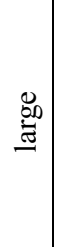 & $\begin{array}{l}8 \\
0 \\
1 \\
\infty \\
\pm \\
-1\end{array}$ & 今ి & 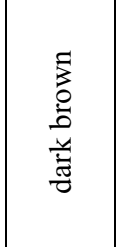 & 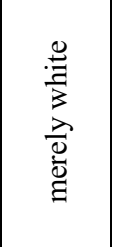 & $\begin{array}{l}\vec{J} \\
\overline{0} \\
0 \\
0 \\
0 \\
0\end{array}$ & 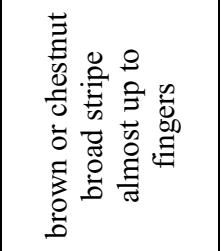 & 壱 & 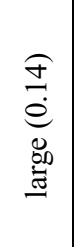 & 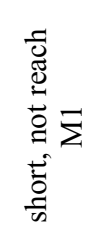 & $\begin{array}{l}\bar{z} \\
\overline{0} \\
\frac{0}{D} \\
\bar{d} \\
\bar{\Xi} \\
\Xi\end{array}$ & $\mid \begin{array}{l}z \\
0 \\
0 \\
= \\
\Xi \\
=\end{array}$ & $\bar{\wedge}$ \\
\hline & 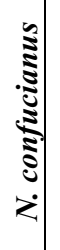 & 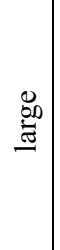 & 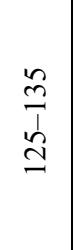 & 今े & 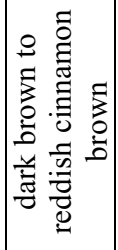 & 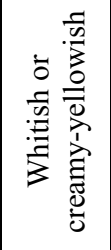 & 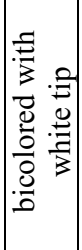 & 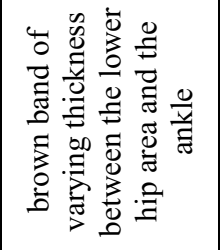 & $\begin{array}{l}\vec{\Xi} \\
\text { 䓌 } \\
\text { 品 }\end{array}$ & 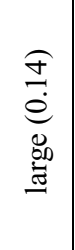 & 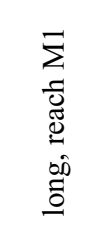 & 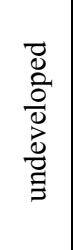 & $\left|\begin{array}{|l}\tilde{J} \\
0 \\
0 \\
0\end{array}\right|$ & $\vec{v}$ \\
\hline & & 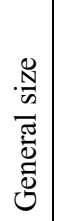 & 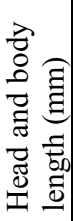 & 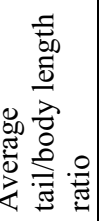 & 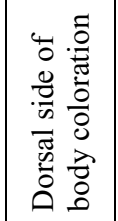 & 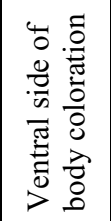 & 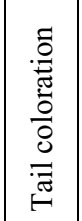 & 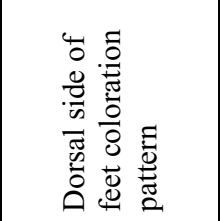 & 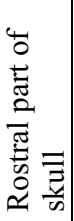 & 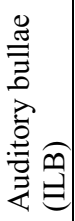 & 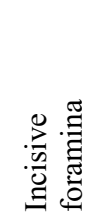 & 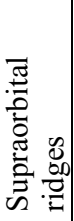 & 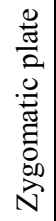 & 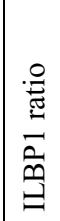 \\
\hline
\end{tabular}


may also contribute to problems in the taxonomy of Niviventer spp.

In order to avoid confusion in species attribution and genus taxonomy we argue that geographically extensive and statistically significant investigations of morphology based on museum craniological materials are to be supported by applying a learning sample constructed from genetically identified specimens.

ACKNOWLEDGMENTS. This study was performed and supported by the Joint Vietnam-Russian Tropical Research and Technological Centre, South Division, Ho Chi Minh City, Vietnam. We thank Dr. V.V. Suntsov, Dr. N.I. Suntsova, A.V. Shchinov and D.A. Makarov (all from the A.N. Severtsov Institute of Ecology and Evolution, Russian Academy of Sciences, Moscow, Russia), Dr. S.V. Kruskop (the Zoological Museum of Moscow State University, Moscow, Russia) who supplied us with a significant number of the specimens. We also thank the administrations of Nam Cat Tien, Bi Dup - Nui Ba, Phu Quoc, Con Dao, Ngoc Linh and Hoang Lien National Parks, Bu Gia Map, Lo Go Xa Mat, Vinh Cuu, and Binh Chau Nature Reserves for help with managing our research. We are very grateful to Dr. L.A. Lavrenchenko and Dr. S.V. Kruskop for their helpful and constructive comments on the early version of the manuscript. This work was supported in part by Ministry of Education and Science of the Russian Federation.

\section{References}

Abe H. 1983. Variation and taxonomy of Niviventer group of rats in Thailand // Journal of Mammalogical Society of Japan. Vol.9. P.151-161.

Allen G.M. 1926. Rats (genus Rattus) from the Asiatic Expeditions // American Museum Novitates. No.217. P.1-16.

Allen G.M. 1940. The Mammals of China and Mongolia. Part 2. New York: American Museum of Natural History. P.621-1350.

Balakirev A.E. \& Rozhnov V.V. 2010. Phylogenic relationships and species composition in the genus Niviventer (Rodentia: Muridae) based on studies of the cytochrome $b$ gene of mtDNA // Moscow University Biological Sciences Bulletin. Vol.65. No.4. P.171-174.

Bekasova T.S. 1984. [Evolution of karyotypes in the subgenus Rattus (Rodentia, Muridae)] // Sokolov V.E. (ed.) [Evolutionary Studies. Macroevolution]. Moskva: Nauka. P.140-158 [in Russian].

Bonhote J.L. 1903. On new species of Mus from Borneo and the Malay Peninsula // The Annals and Magazine of Natural History, Including Zoology, Botany, and Geology. Vol.11. Ser.7. P.123-125.

Bonhote J.L. 1906. The mammalian fauna of China. Part I. Murinae // Proceedings of Zoological Society of London. Vol.2. P.384-397.

Corbet G.B. \& Hill J.E. 1992. The Mammals of the IndoMalayan Region: A Systematic Review. Oxford: Oxford University Press. 488 p.
Dang Huy Huynh, Dao Van Tien, Cao Van Sung, Pham Trong Anh \& Hoang Minh Khien. 1994. [Checklist of Mammals in Vietnam]. Hanoi: Publishing House Science and Technics. 167 p. [in Vietnamese].

Dang Ngoc Can, Endo H., Nguyen Truong Son, Oshida T., Le Xuan Canh, Dang Huy Phuong, Lunde D.P., Kawada S.-I., Hayashida A. \& Sasaki M. 2008. [Checklist of Wild Mammal Species of Vietnam]. Hanoi: Institute of Ecology and Biological Resources. 400 p. [in Vietnamese].

Duncan J.F., Van Peenen P.F.D. \& Ryan P.F. 1970. Somatic chromosomes of eight mammals from Con Son Island, Southern Vietnam // Caryologia. Vol.23. P.173-181.

Duncan J.F. \& Van Peenen P.F.D. 1971. Karyotypes of ten rats (Rodentia: Muridae) from Southeast Asia // Caryologia. Vol.24. P.331-346.

Ellerman J.R. 1941. The Families and Genera of Living Rodents. Vol.2. Family Muridae. London: British Museum (Natural History). 690 p.

Ellerman J.R. 1947. A key to the Rodentia inhabiting India, Ceylon, and Burma, based on collections in the British Museum // Journal of Mammalogy. Vol.28. P.249-278.

Ellerman J.R. 1948. Key to the rodents of south-west Asia in the British Museum collection // Proceedings of the Zoological Society of London. Vol.118. Pt.3. P.765816.

Ellerman J.R. 1949. The Families and Genera of Living Rodents. Vol.3. Pt.1. London: British Museum (Natural History). $210 \mathrm{p}$.

Ellerman J.R. 1961. The Fauna of India, Including Pakistan, Burma and Ceylon: Mammalia. Second edition. Vol.3. Rodentia. Part 1-2. Calcutta: Zoological Survey of India. $884 \mathrm{p}$.

Ellerman J.R. \& Morrison-Scott T.C.S. 1951. Checklist of Palaearctic and Indian Mammals, 1758 to 1946. London: British Museum of Natural History. 810 p.

Ellerman J.R. \& Morrison-Scott T.C.S. 1966. Checklist of Palaearctic and Indian Mammals, 1758 to 1946. Second edition. London: British Museum of Natural History. $810 \mathrm{p}$.

Felsenstein J. 1981. Evolutionary trees from DNA sequences: a maximum likelihood approach // Journal of Molecular Evolution. Vol.17. No.6. P.368-376.

Francis C.M. 2008. A Guide to the Mammals of Southeast Asia. Princeton and Oxford: Princeton University Press. $392 \mathrm{p}$.

Hall T.A. 1999. BioEdit: a user-friendly biological sequence alignment editor and analysis program for Windows 95/ 98/NT // Nuclear Acids Symposium. Ser.41. P.95-98.

Hebert P.D.N., Cywinska A., Ball S.L. \& deWaard J.R. 2003. Biological identifications through DNA barcodes // Proceedings of the Royal Society of London, Series B. Vol.270. P.313-321.

Irwin D., Kocher T.D. \& Wilson A.S. 1991. Evolution of the cytochrome $b$ gene of mammals // Journal of Molecular Evolution. Vol.32. P.128-144.

Jansa S.A., Barker F.K. \& Heaney L.R. 2006. The pattern and timing of diversification of Philippine endemic rodents: evidence from mitochondrial and nuclear gene sequences // Systematic Biology. Vol.55. No.1. P.73-88. 
Jing M., Yu H.-T., Wu S.-H., Wang W. \& Zheng X. 2007. Phylogenetic relationships in genus Niviventer (Rodentia: Muridae) in China inferred from complete mitochondrial cytochrome $b$ gene // Molecular Phylogenetic and Evolution. Vol.44. P.521-529.

Jiang Q. 1995. Study on chromosomal classification of Rattus confucianus and $R$. fulvescens // Journal of Sun Yatsen University. Vol.1. P.98-103.

Kocher T.D., Thomas W.K., Meyer A., Edwards S.V., Pääbo S., Villablanca F. \& Wilson A. 1989. Dynamics of mitochondrial DNA evolution in animals: amplification and sequencing with conserved primers // Proceedings of National Academy of Sciences of USA. Vol.86. P.61966200.

Kuznetsov G.V. 2006. [Mammals of Vietnam]. Moskva: KMK Scientific Press Ltd. 420 p. [in Russian].

Lecompte E., Aplin K., Denys Ch., Catzeflis F., Chades M. \& Chevret P. 2008. Phylogeny and biogeography of African Murinae based on mitochondrial and nuclear gene sequences, with a new tribal classification of the subfamily // BMC Evolutionary Biology. Vol.8. P.199.

Li Y., Wu Y., Harada M., Lin L-K. \& Motokawa M. 2008. Karyotypes of three rat species (Mammalia: Rodentia: Muridae) from Hainan Island, China, and the valid specific status of Niviventer lotipes // Zoological Science. Vol.25. P.686-692.

Lunde D.P. \& Nguyen Truong Son. 2001. An Identification Guide to the Rodents of Vietnam. New York: Center for Biodiversity and Conservation, American Museum of Natural History. $80 \mathrm{p}$.

Lunde D.P., Nguyen Truong Son \& Musser G.G. 2007. A survey of small mammals from Huu Lien Natural Reserve, Lang Son Province, Vietnam // Mammal Study. Vol.32. P.155-168.

Markvong A., Marshall J.T. \& Gropp A. 1973. Chromosomes of rats and mice of Thailand // Natural History Bulletin of Siam Society (Biological Sciences). Vol.25. P. 233-240.

Marshall J.T. 1977. Family Muridae (rats and mice) // Lekagul B. \& McNeely G. Mammals of Thailand. Bangkok: Kurusapha Ladprao. P.397-487.

Mayr E. 1963. Animal Species and Evolution. Cambridge: Harvard University Press. 597 p.

Miller G.S. 1900. Seven new rats collected by Dr. W.L. Abbott in Siam // Proceedings of Biological Society Washington. Vol.13. P.137-150.

Misonne X. 1969. African and Indo-Australian Muridae; evolutionary trends // Annales of Museum of Royal African Centre of Tervuren, Zoology. Vol.172. P.1-219.

Molur S., Srinivasulu C., Srinivasulu B., Walker S., Nameer P.O. \& Ravikumar L. 2005. Status of Non-volant Small Mammals: Conservation Assessment and Management Plan Workshop Report. Comibatore: Zoo Outreach Organization / CBSG-South Asia. 618 p.

Musser G.G. 1973. Species-limits of Rattus cremoriventer and Rattus langbianis, murid rodents of southeastern Asia and the Greater Sunda Islands // American Museum Novitates. No.2525. P.1-65.

Musser G.G. 1981. Results of the Archbold expeditions, No.105. Notes on systematics of Indo-Malayan murid rodents and descriptions of new genera and species from
Ceylon, Sulawesi and the Philippines // Bulletin of American Museum (Natural History). Vol.168. No.3. P.236256.

Musser G.G. \& Carleton M.D. 1993. Family Muridae // Wilson D.E. \& Reeder D.M. (eds.). Mammal Species of the World. A Taxonomic and Geographic Reference. Second edition. Washington: Smithsonian Institution Press. P.501-755.

Musser G.G. \& Carleton M.D. 2005. Superfamily Muroidea // Wilson D.E. \& Reeder D.M. (eds.). Mammals Species of the World. A Taxonomic and Geographic Reference. Third edition. Vol.2. Baltimore: Johns Hopkins University Press. P.894-1531.

Musser G.G. \& Heaney L.R. 1992. Philippine rodents: definitions of Tarsomys and Limnomys plus a preliminary assessment of phylogenetic patterns among native Philippine murines (Murinae, Muridae) // Bulletin of the American Museum of Natural History. Vol.211. P.1-138.

Musser G.G. \& Newcomb C. 1983. Malaysian murids and the giant rat of Sumatra // Bulletin of the American Museum of Natural History. Vol.174. P.327-598.

Musser G.G., Lunde D.P. \& Nguyen Truong Son. 2006. Description of a new genus and species of rodent (Murinae, Muridae, Rodentia) from the Tower Karst Region of Northeastern Vietnam // American Museum Novitates. No.3517. P.1-41.

Musser G., Lunde D., Aplin K. \& Molur S. 2008. Niviventer fulvescens // IUCN 2011. IUCN Red List of Threatened Species. Version 2011.1. <www.iucnredlist.org>. Downloaded on 08 July 2011.

Niethammer J. \& Martens J. 1975. Die gattungen Rattus und Maxomys in Afghanistan und Nepal // Zeitschrift für Säugetierkunde. Vol.40. P.325-355.

Nowak R.M. 1999. Walker's Mammals of the World. Sixth edition. Baltimore and London: The Johns Hopkins University Press. Vol.2. P.837-1936.

Osgood W.H. 1932. Mammals of the Kelley-Roosevelt and Delacour Asiatic expeditions // Fields Museum of Natural History Publications. Vol.18. P.193-339.

Page R.D.M. 1996. Tree View: An application to display phylogenetic trees on personal computers // Computers and Applied Bioscience. Vol.12. No.4. P.357-358.

Pagés M., Chaval Y., Herberteau V., Waengsothorn S., Cosson J-F., Hugot J.-P., Morand S. \& Michaux J. 2010. Revisiting the taxonomy of the Rattini tribe: a phylogeny based delimitation of species boundaries // BMC Evolutionary Biology. Vol.10. P.184.

Pavlinov I.Ya. 2005. [Systematic of Recent Mammals]. Second Edition. Moskva: Izdatel'stvo Moskovskogo Universiteta. 297 p. [In Russian].

Robins J.H., Hingston M., Matisoo-Smith E. \& Ross H.A. 2007. Identifying Rattus species using mitochondrial DNA // Molecular Ecology Notes. Vol.7. P.717-729.

Robinson H.C. \& Kloss C.B. 1922. New mammals from French Indo-China and Siam // Annals and Magazine of Natural History (Zoology, Botany and Geology). Vol.9. P.87-99.

Sambrook J., Fritsch E.F. \& Maniatis T. 1989. Molecular Cloning: A Laboratory Manual, Cold Spring Harbor: Cold Spring Harbor Lab. 256 p.

Savolainen V., Cowan R.S., Vogler A.P., Roderick G.K. \& Lane R. 2005. Towards writing the encyclopedia of life: 
an introduction to DNA barcoding // Philosophical Transactions of the Royal Society of London, Series B. Vol.60. P.1805-1811.

Smith A.T. \& Lunde D. 2008. Family Muridae // Smith A.T. $\&$ Yan Xie. A Guide to the Mammals of China. Princeton and Oxford: Princeton University Press. P.247-273.

StatSoft, Inc. 2001. STATISTICA (data analysis software system), version 6. www.statsoft.com.

Stephen C. \& Rudolf M. 2007. Contribution to the taxonomic status of the Chinese rats Niviventer confucianus and N. fulvescens // Mammalian Biology. Vol.72. No.4. P.213-222.

Tamura K., Dudley J., Nei M. \& Kumar S. 2007. MEGA 4: Molecular Evolutionary Genetics Analysis (MEGA) software version 4.0 // Molecular Biology and Evolution. Vol.24. P.1596-1599.

Thomas O. 1916. A new rat from Tenasserim // Annals and
Magazine of Natural History (Zoology, Botany and Geology). Vol.17. P.425.

Van Peenen P.F.D. 1969. Preliminary Identification Manual for Mammals of South Vietnam. Washington: United States National Museum, Smithsonian Institution. 193 p.

Wang Y.X. 2003. A Complete Checklist of Mammal Species and Subspecies in China: A Taxonomic and Geographic Reference. Beijing: China Forestry Publishing House. 394 p. [in Chinese with English foreword].

Zhang Y., Jin S., Quan G., Li S., Ye Z., Wang F. \& Zhang M. 1997. Distribution of Mammalian Species in China. Beijing: China Forestry Publishing House. 280 p.

Yong H.S. 1969. Karyotypes of Malay rats (Rodentia: Muridae, genus Rattus Fischer) // Chromosoma. Vol.27. P.245-267.

Yoshida T.H. 1973. Evolution of karyotypes and differentiation in 13 Rattus species // Chromosoma. Vol.40. P.285-297.

\section{APPENDIX I}

\section{List of Vietnamese localities (numbers shown in Fig. 1).}

1. Lao Cai Province, Hoang Lien National Park, $22^{\circ} 20^{\prime} \mathrm{N}, 103^{\circ} 50^{\prime}$ E, elevation $1930-2200 \mathrm{~m}$ a.s.l.

2. Kon Tum Province, Ngoc Linh National Park, Lo Xo Pass, $15^{\circ} 15^{\prime} \mathrm{N}, 107^{\circ} 44^{\prime}$ E, elevation $800 \mathrm{~m}$ a.s.l.

3. Khanh Hoa Province, Hon Ba Nature Reserve, $12^{\circ} 07^{\prime} \mathrm{N}, 108^{\circ} 57^{\prime} \mathrm{E}$, elevation $1500 \mathrm{~m}$ a.s.l.

4. Dak Lak Province, Yok Don National Park, $12^{\circ} 58^{\prime} \mathrm{N}, 107^{\circ} 49^{\prime}$ E, elevation $250 \mathrm{~m}$ a.s.l.

5. Lam Dong Province, Bi Dup - Nui Ba National Park, $12^{\circ} 10^{\prime} 44^{\prime \prime} \mathrm{N}, 108^{\circ} 40^{\prime} 44^{\prime \prime} \mathrm{E}$, elevation 1400-2070 m a.s.l.

6. Tay Ninh Province, Lo Go Xa Mat Nature Reserve, $11^{\circ} 35^{\prime} \mathrm{N}, 105^{\circ} 56^{\prime}$ E, elevation 50-120 m a.s.l.

7. Binh Phuong Province, Bu Gia Map Nature Reserve, $12^{\circ} 11^{\prime} 37^{\prime \prime} \mathrm{N}, 107^{\circ} 12^{\prime} 21^{\prime \prime}$ E, elevation $540 \mathrm{~m}$ a.s.l.

8. Dong Nai Province, Nam Cat Tien National Park, $11^{\circ} 26^{\prime} 23^{\prime \prime} \mathrm{N}, 107^{\circ} 24^{\prime} 55^{\prime \prime}$ E, elevation $100 \mathrm{~m}$ a.s.l.

9. Dong Nai Province, Vinh Cuu Nature Reserve (= Ma Da Forest), $11^{\circ} 22^{\prime} 51^{\prime \prime} \mathrm{N}, 107^{\circ} 03^{\prime} 44^{\prime \prime}$ E, elevation $100 \mathrm{~m}$ a.s.l.

10. Ba Ria - Vung Tau Province, Bihn Chau Nature Reserve, $10^{\circ} 32^{\prime} \mathrm{N}, 107^{\circ} 29^{\prime} \mathrm{E}$, elevation $\sim 50 \mathrm{~m}$ a.s.l.

11. Kien Giang Province, Phu Quoc Island, Phu Quoc National Park, $10^{\circ} 22^{\prime} 05^{\prime \prime} \mathrm{N}, 104^{\circ} 00^{\prime} 19^{\prime \prime}$ E, elevation 25 $480 \mathrm{~m}$ a.s.1.

12. Ba Ria - Vung Tau Province, Con Son Island, Con Dao National Park, $08^{\circ} 41^{\prime} 31^{\prime \prime} \mathrm{N}, 106^{\circ} 36^{\prime} 17^{\prime \prime}$ E, elevation 200-300 m a.s.1.

\section{APPENDIX II \\ Specimens examined (skulls, skins).}

Niviventer fulvescens (11 specimens): Hoang Lien National Park, Lao Cai Province (ZIN: 97697, 97702, 97703, 97705; ZMMU: S-184805-184810, S-184825).

Niviventer huang (12 specimens): Nam Cat Tien National Park, Dong Nai Province (ZMMU: S-184811-184813); Lo Go Xa Mat Nature Reserve, Tay Ninh Province (ZMMU: S-184814-184817); Ngoc Linh National Park, Kon Tum Province (ZIN: 91152-91156).

Niviventer niviventer (8 specimens): Hoang Lien National Park, Lao Cai Province (ZIN: 97700, 97704; ZMMU: S-184819-184824).

Niviventer confucianus (2 specimens): Hoang Lien National Park, Lao Cai Province (ZIN 97698, 97701).

Niviventer bukit (26 specimens): Bi Dup - Nui Ba National Park, Lam Dong Province (ZIN: 97681, 97691, 97692, 97694, 97695, 97701); Nam Cat Tien National Park, Dong Nai Province (ZMMU: S-184787-184804, S-186943, S-186944).

Niviventer tenaster (7 specimens): Bi Dup - Nui Ba National Park, Lam Dong Province (ZIN: 97686, 97693, 97698, 97699; ZMMU: S-184826, S-184827, S-184830).

Niviventer langbianis (8 specimens): Bi Dup - Nui Ba National Park, Lam Dong Province (ZIN: 96516, 97678 97680, 97682-97685).

Niviventer cremoriventer (2 specimens): Vinh Cuu Nature Reserve (= Ma Da Forest), Dong Nai Province (ZMMU S-186116); Lo Go Xa Mat Nature Reserve, Tay Ninh Province (ZMMU S-184818). 


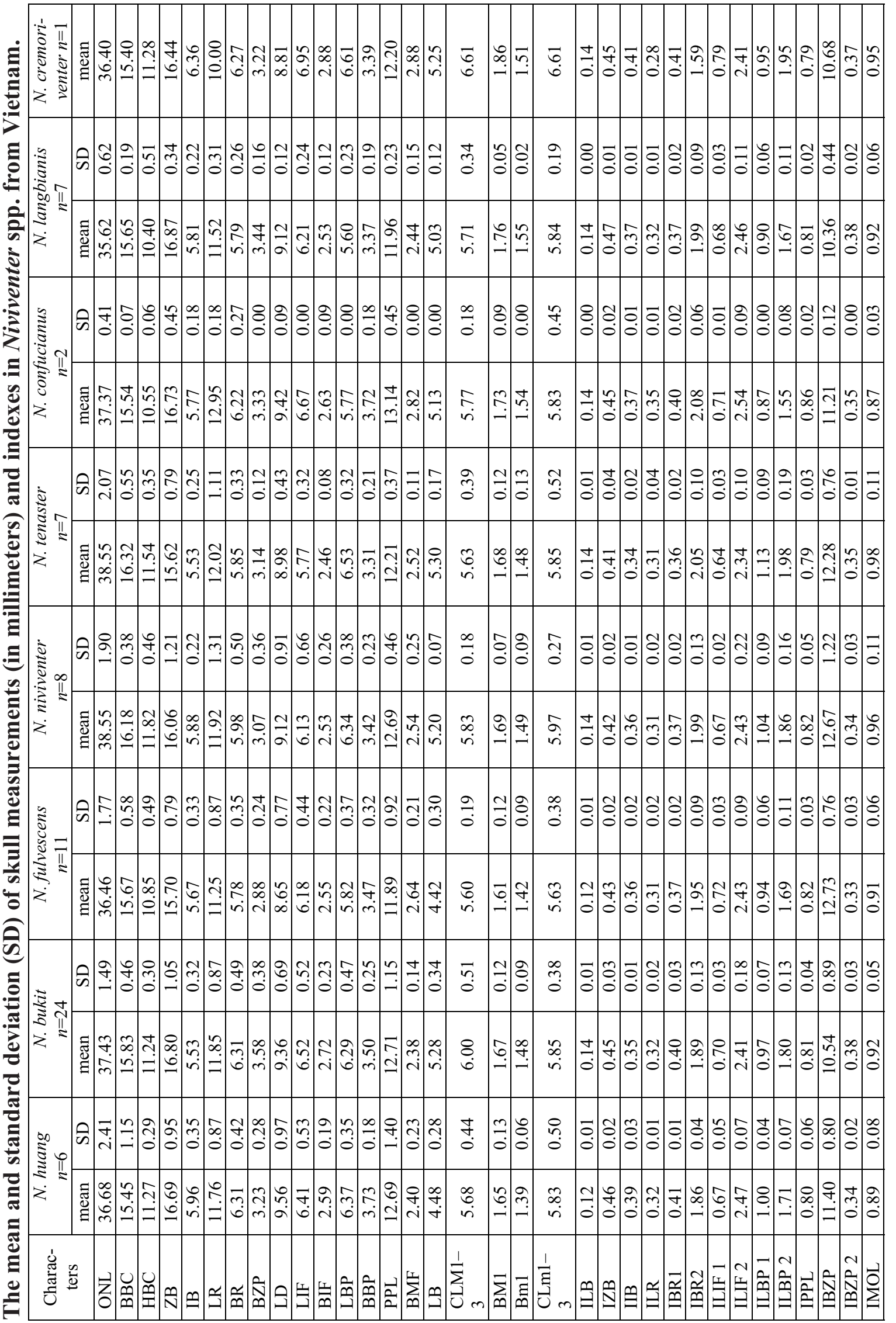


APPENDIX IV

Classification functions and variable loadings for the discriminant analysis.

\begin{tabular}{|l|c|c|c|c|c|c|c|}
\hline \multirow{2}{*}{} & \multicolumn{7}{|c|}{ Classification functions } \\
\cline { 2 - 9 } & N. huang & N. bukit & N. fulvescens & N. niviventer & N. tenaster & N. confucianus & N. langbianis \\
\hline IBZP & 30.420 & 28.659 & 32.057 & 31.186 & 30.504 & 30.372 & 27.947 \\
\hline ILBP 1 & 220.240 & 193.873 & 199.132 & 211.146 & 239.501 & 165.583 & 168.445 \\
\hline ILB & -592.282 & 131.185 & -431.876 & -4.913 & 54.612 & 135.426 & 66.672 \\
\hline IZB & 755.459 & 600.126 & 686.802 & 534.396 & 462.433 & 537.027 & 679.000 \\
\hline ILR & 149.236 & 230.529 & 253.668 & 317.731 & 437.033 & 376.268 & 169.128 \\
\hline IBR 1 & 797.883 & 794.572 & 731.614 & 729.509 & 730.284 & 736.187 & 663.354 \\
\hline IIB & 404.208 & 228.067 & 339.607 & 331.487 & 198.878 & 299.260 & 394.345 \\
\hline Constant & -686.346 & -624.898 & -657.049 & -664.503 & -656.241 & -642.902 & -611.729 \\
\hline
\end{tabular}

